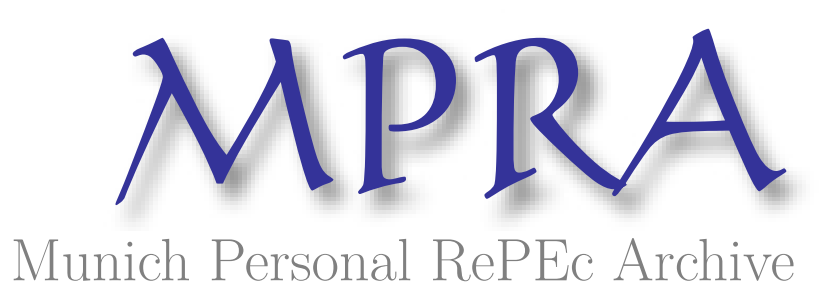

\title{
Do Human Restriction Mobility Policy in Indonesia effectively reduce The Spread of COVID-19
}

Satyakti, Yayan

University of Padjadjaran

18 July 2020

Online at https://mpra.ub.uni-muenchen.de/101911/

MPRA Paper No. 101911, posted 24 Jul 2020 10:04 UTC 


\title{
Do Human Restriction Mobility Policy in Indonesia effectively reduce The Spread of COVID-19
}

\author{
Yayan Satyakti ${ }^{\S}$ \\ First Draft July 2020 \\ Department of Economics, \\ Faculty of Economics and Business \\ University of Padjadjaran
}

\begin{abstract}
Since COVID-19 spread across the globe. Every country has attempted to reduce the spread by containment policy. Indonesia as one of the hot spot countries in South East Asia has been conduct this policy to reduce the spread. The Indonesian government introduce partial lockdown policy that called as Large Scale of Social Restriction (PSBB) in some regions. This paper examined the interaction between restriction of human mobility policy on spreading of COVID-19 confirmed case. I proxied human mobility dataset by hourly report of car congestion traffic from Waze application with sub level district. The COVID-19 confirm case retrieved from official government report with province level. In order to measure the impact of this policy, I conducted regression discontinuity design using consistent panel dataset across sub level district and daily frequency. The result indicates that the containment policy has various impact on other reduce. The policy that impact in adequate region such as DKI Jakarta has effectively reduced about $60 \%$ $70 \%$ of spreading COVID-19 confirmed case. Whereas the region with vast area such as West Java is depend on neighbor area less effectively impact on spreading COVID-19 confirm case. The model has produced robust estimation that containment policy will reduced human mobility on COVID-19 confirmed case.
\end{abstract}

Keywords: epidemic model, regression discontinuity, econometric, spatial model, Waze, car congestion report.

\section{Introduction}

Since December 2019, the impact of spread COVID-19 virus has spread across the globe. This virus has infected globally and ravaging many countries in the world (Gatto et al., 2020). Indonesia's has promoted partial lockdown policy according to Government Regulation No. 21 Year 2020 about Large Scale Social Restriction (PSBB) to Accelerate Limiting Corona Virus Disease 2019 (COVID-19). The PSBB is partial lockdown policy that Indonesian government attempt to reduce the impact of physical distancing on the economy activity. According to latest news about 18 cities and municipalities have managed this policy. In some parts of regions, this policy has decreased the COVID-19 spread, otherwise others are not reduce yet significantly.

On the other hands, in the latest months the policy has been questioned. ${ }^{2}$ Since relaxing the containment policy in the early of June. The increasing of additional positive case is remain high. ${ }^{3}$ In fact, after some region released the containment policy, the new number of COVID-19 case is hike in new area such as East Java ${ }^{4}$. If we treat that this policy as a random experiment, what is a magnitude parameter in area that quasi randomly assigned the PSBB have better impact on reducing the spread of COVID-19. I approach this

\footnotetext{
§ yayan@unpad.ac.id. Jl. Dipati Ukur No. 35 Bandung, Indonesia 40115.

2 https://www.cnbc.com/2020/04/20/southeast-asia-could-be-the-next-coronavirus-hot-spot-these-charts-show-why.html

${ }^{3}$ https://en.tempo.co/read/1349358/daily-new-cases-still-high-as-jakartas-3rd-psbb-ends-tomorrow

${ }^{4}$ https://www.who.int/docs/default-source/searo/indonesia/covid19/who-situation-report-11.pdf?sfvrsn=a5ee6cc2 2
} 
research question into three closely related queries that is first, whether PSBB policy reduce COVID-19 spread. Second, whether regions surrounding the PSBB regions, have benefited from this policy. Last but not least, third analysis will predict unreported case with and without policy option.

One of major problem treating human restriction policy is estimating the true of spreading COVID-19 case. It has been common, that under reporting of confirmed case by the government stimulate strain effect for the society whether new normal will be start and end the lockdown policy. Therefore, it is necessary measuring human activity that stimulate spread COVID-19 will help policy makers to evaluate whether existing policy have effectively tackled the problem or not. There are several approaches has been promoted to estimate the human restriction policy such to reduce COVID-19 spread. The study has conducted by Fang et al., (2020) who studies about Lockdown Policy in China and Wuhan region. Gatto et al. (2020)who study the effect of containment policy on spread of COVID-19 in Italy. While others studies such as Alvarez et al. (2020) study about optimal lockdown policy that stated identifying early of infection will shorten duration of optimal lockdown. In addition such as Fogli and Veldkamp (2020) has studied how the germs and social network impact on economic growth with global data.

In order to assess the spreading of COVID-19 by human mobility across spatial. I measured that human mobility proxies with road traffic congestion. This approaches has supported by Gatto et al., (2020) who report that spreading of epidemic along highways and transportation infrastructures. On the other hand, the data availability along with average location will be very crucial to estimate when the data can be represent properly to estimate the outcome we can predict how this exogenous variation in access of car congestion report network affect on spreading of COVID-19. We require real time data to measure this mobility with consistent on location and time frequency. It is important that that containment policy should measure whether the policy impact may reduce spreading COVID-19 to surrounding region.

I employed Waze Mobility Report as a proxy of car traffic congestion which provides detail in terms of hours mobility across regions in Indonesia. Although in terms of data mobility, mostly of sample available represent in Java Island. This data also fit for Indonesia's culture mobility. Indonesia is lack of proper public transportation system especially in urban area (Roberts et al., 2019). It's produced long time travel, expensive transport cost to integrate interurban connectivity across large metropolitan area. Most of commuters depend upon private cars rather than public transportation system. Therefore, I choose this indicator as a proper proxy to represent human mobility connection and flow across spatial boundaries.

In addition, this mobility report also has detail information about location of car report congestion with Global Position System (GPS) across time and space. Therefore, this data can be mapped and generated along with COVID-19 case consistently. While other study apply human flow mobility with origin and destination matrix such Fang et al. (2020), or Pepe et al. (2020) estimate mobility changes with geolocated of smartphone. This paper offer different approach, although the data generated with smartphone, the car report congestion application produce traffic condition that indicates human intensity that accumulate their social network mobility in particular area such as shopping mall, residence, entertainment park and others. In line with other studies such as Gatto et al. (2020), Pepe et al., (2020), and Charu et al. (2017). I assumed that COVID-19 spreading triggered spatially through traffic flow across city and regions boundaries. When the policy is enacted. We can figure out how the policy reduce COVID-19 in respective region and other region surrounding the COVID-19 center.

\section{Model Setup}

The basic idea of this paper is estimating whether PSBB policy reduce spreading of COVID-19 or not. In order to assess this policy I should evaluated whether with or without containment policy (PSBB) affect on 
spread of COVID-19 confirmed case. This idea close to study conducted by Hsiang et al., (2020) who study anti contiguous policy (containment policy) across countries on reducing spread of COVID-19. Their study estimate how with or without policy affect such as emergency declaration, travel ban, home isolation affect on reducing spread.

This paper also has similar objectives but with different methodology. I assessed without policy by estimating the baseline as a control group without policy period. Estimating without policy period is necessary to estimate how many people will be affected without the containment policy. In order to distinguish this approach and easy to track the policy. We can use difference in difference with regression discontinuity (DID-RD). The advantage of this approach we can evaluated whether with policy produce more outcome rather than not with randomized experiment. When this policy enacted within specific region, some of household or people will obey or disobey the policy. We can see that this treatment policy will be randomized impact along with the policy that force people to reduce their mobility.

We can estimate the line of jumped on $\mathrm{x}$ axis by localized treatment effect for the people who obey the rule as a threshold or cut off value. If there is a jump between this threshold value we can evaluated the magnitude the outcome will jump across the local estimation. The design of RD method rigorously have been studied by Imbens and Lemieux (2008) and Lee and Lemieux (2010). My paper will focus the design of regression discontinuity by depicting hypothetical graph in Figure 1.

\section{Figure 1. Regression Discontinuity Design for treatment of containment policy of COVID-19 spread}
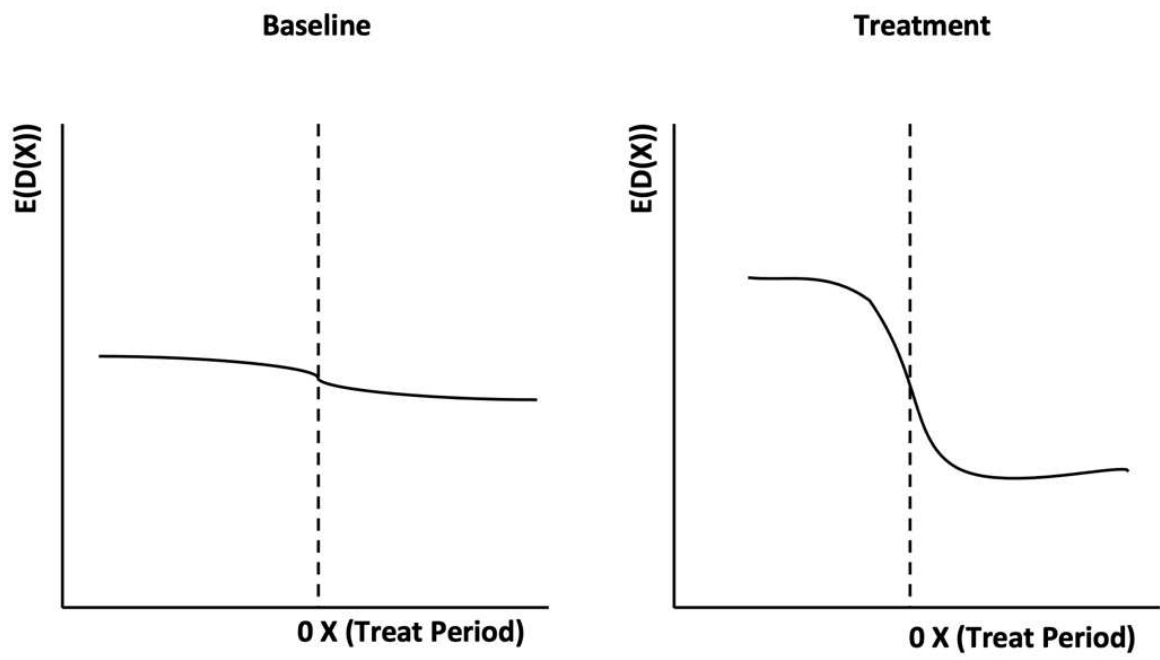

In Figure 1, indicates that baseline panel without policy COVID-19 will be continuously spread and increasing of COVID-19 confirmed case. Although there is a small changes due to people awareness without any policy at all. In treatment panel, we can see there is a significant jump between pre treatment and after treatment.

To estimates for both baseline and treatment graph. The first step, we should estimate how much outcome without policy affect on COVID-19 spread. Whether without policy produce continuous results along with treatment period. In order to accommodate this analysis. We should estimate the unobserved control group 
in the model by estimating without policy treatment. The second step, is estimating treatment panel whether the jump is exist and produce impact in the treatment graph. Finally, we test the jump effect by seemingly unrelated estimation between the two groups between control as a baseline and treatment. Whether parameter is well enough to inform the impact. While this paper investigates the impact of regional policy with spatial boundary. I followed Keele and Titiunik (2015) procedure to performed regression discontinuity framework by applying in geographic boundaries.

If we looking at on geographic map the containment policy or PSBB in Indonesia. Only two provinces were conducted this policy that is DKI Jakarta and West Java. According to Keele and Titiunik (2015), applying regression discontinuity for geographic boundaries will be hard without applying geographic distance with selected point of spatial impact.

I assumed that first PSBB policy enacted in DKI Jakarta will impact on Java Island where this island has hit the most of COVID-19 spread. I prefer the analysis focus in this island. While the human restriction mobility data also has more sample rather than other island. The analysis will be conducting at least in geographical direction scenario. That is DKI Jakarta - Banten impact, DKI Jakarta - West Java impact. The following region that conducted similar policy with DKI Jakarta that is West Java. The PSBB's policy of West Java will be impact on three respected regions that is West Java - DKI Jakarta impact, West Java - DKI Jakarta Impact, West Java - Banten Impact, and West Java - Central Java Impact. For detail scenario I depicted in Figure 2.

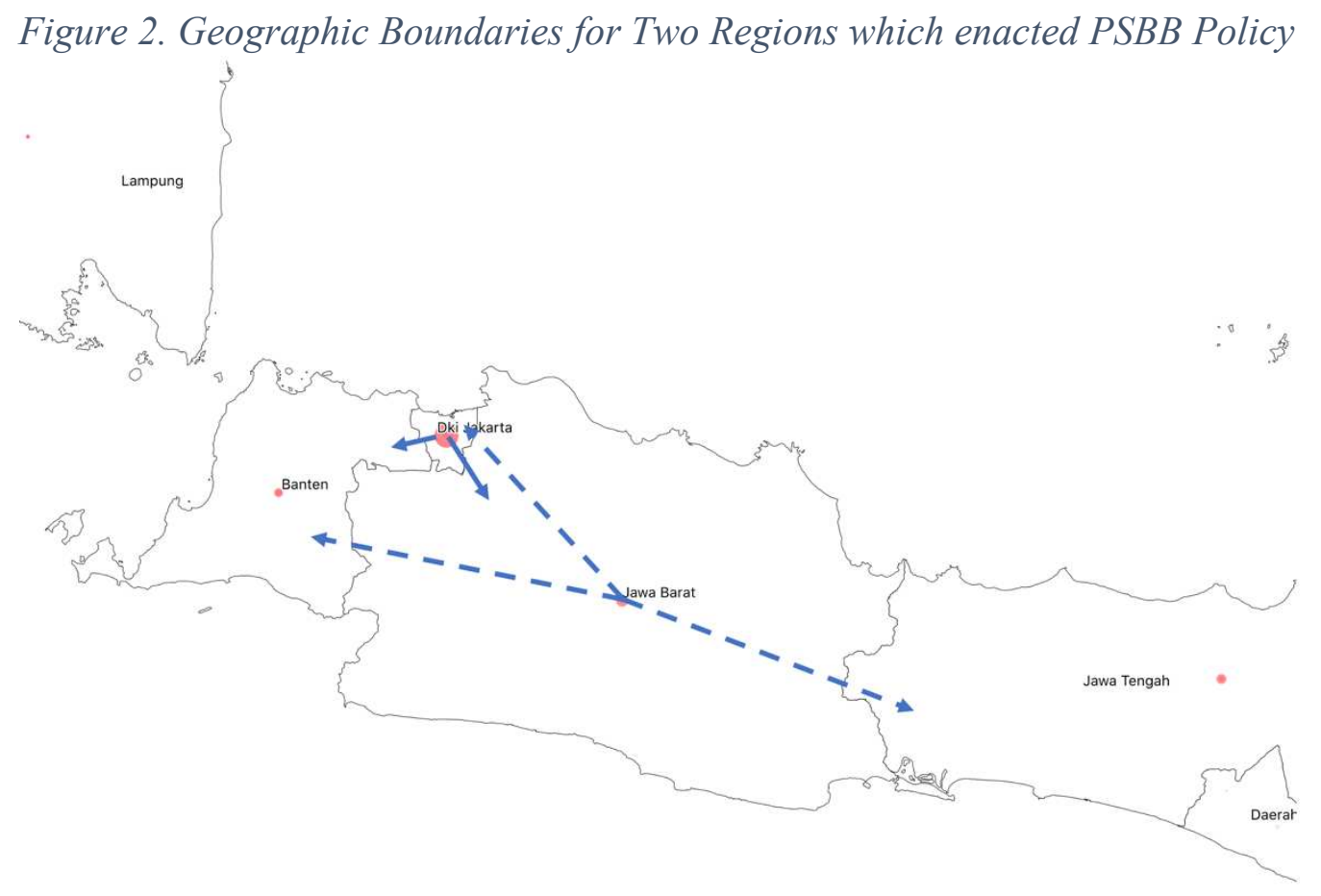

Note: Jawa Barat $=$ West Java; Jawa Tengah $=$ Central Java

In order to evaluated in which region has bigger impact we can measure by comparing two coefficients from respected scenarios with the formula: 
(1) $\Delta_{\tau}^{\mathrm{e}}=\frac{\beta_{\tau}^{e}}{\beta_{c}^{e}}$

Where $\Delta_{\tau}^{\mathrm{e}}$ is the impact value between two parameters compare to others scenarios $(\boldsymbol{e}), \tau$ is a treatment policy region within particular period, and $c$ control policy within control period.

\subsection{Epidemic Model}

I adopted epidemic model according to Charu et al. (2017) that increasing incident of COVID-19 in one location determined by works commutes and other transportation means that connect social interaction. The equation consist of

(2) $\ln C_{r t}=\alpha_{0}+\alpha_{1} \ln V_{r t}+\alpha_{2} R_{r t}+\alpha_{3} T_{r t}+\alpha_{4} D_{r s t}+\eta_{r t}+\epsilon_{r t}$

Where $\alpha_{0}$ is constant in the epidemic model, $\mathrm{r}$ is a sub district at lowest level of administrative boundaries, $\mathrm{s}$ is sub district within center of infected area. $\mathrm{C}$ is additional infected case in province level, and $\mathrm{V}$ is human mobility that proxied by work commutes that indicates by traffic report congestion. $\mathrm{R}$ is region that conducted containment policy, $\mathrm{T}$ is a treatment period which region (i.e. province area) conduct containment policy. $\mathrm{D}$ is distance between respective region to center of containment policy. Where $\eta_{r t}$ is sub district time fixed effect and $\epsilon_{r t}$ is clustered by sub district and time. This model is a general form of fixed effect econometric model that indicates how additional of COVID-19's case determined by mobility and treatment effect for both spatial and time in sub district area. In addition, I added D as a proximity effect between infected core area and its surrounding that separated between region with containment policy and without containment policy.

While I focus the individual interaction with unobservable factors that increase of COVID-19 case, such as un-report case that continuously related to additional COVID-19 case. We should aware that the containment policy effect will apply to subpopulation of individual who not obey to this policy. If we start the null hypothesis that without containment policy as a continuous threshold of COVID-19 case between two regions. We can evaluate how through jump parameter as well as jump graph of human mobility that produce lower outcome of COVID-19 spread than continuous threshold in the baseline. We can validate this statemen by conducting regression discontinuity that separated region with and without policy. When the policy in enacted, the human mobility will significantly jump into lower level along with geographic boundaries. This approaches requires particular procedure according to Imbens and Lemieux (2008) and Lee and Lemieux (2010). That border should indicates precisely where the accurate location of geographic boundaries.

I defined that human mobility in the sub district area are accumulated report of traffic report congestion in any point of location by two coordinates of latitude and longitude $\left(v_{x}^{i}, v_{y}^{i}\right)$. This mobility mapped into sub district level of $r$. The accumulated report of $\Sigma_{i=1}^{n}\left(v_{x_{t}}^{i}, v_{y_{t}}^{i}\right)=V_{r, t}$ is traffic congestion report as a proxy of human mobility report. I have two treatment between this spatial area that is $V_{r, t}^{\tau}=V_{r, t}^{c}$. Hence, $V_{r, t}^{\tau}, V_{r, t}^{c}$ is general heterogeneity between two human mobility of treatment effect $\left(V_{r, t}^{\tau}\right)$ and human mobility of control group $\left(V_{r, t}^{c}\right)$. I assumed that containment policy between spatial boundaries has a jump effect and produce discontinuity.

We can separated equation (2) into two conditional regression function according to Imbens and Lemieux (2008) there is a discontinuity between $V_{r, t}^{\tau}$ and $V_{r, t}^{c}$ can be evaluated by assigning two dimensional score at the point of spatial boundary of containment policy of $\beta$ defined as 
(3) $\lim _{v \rightarrow \beta} E\left\{C_{r t}^{c} \mid V_{r t}=v\right\}=E\left\{C_{r t}^{c} \mid V_{r t}=\beta^{c}\right\}$, for region without containment policy

(4) $\lim _{v \rightarrow \beta} E\left\{C_{r t}^{\tau} \mid V_{r t}=v\right\}=E\left\{C_{r t}^{\tau} \mid V_{r t}=\beta^{\tau}\right\}$, for region with containment policy

The treatment policy on human mobility of $V_{r t}^{\tau}$ can distinguished outcome of infected additional COVID19 with $C_{r t}^{\tau}$ than without treatment policy on human mobility of $V_{r t}^{c}$ that produce infected without this policy that is $C_{r t}^{c}$. In region with containment policy where spatial boundaries within $\beta$, reduce COVID-19 spread. Otherwise region without containment policy will reduce surrounding area of containment policy. The policy impact will fade across region when distance is getting remote from the COVID-19 center.

According to assumption in equation (2) and equation (3), I can test the outcome variable as a polynomial function with second degree polynomial function of human restriction mobility policy across entire sub district area. I prefer limited polynomial function according to (Gelman and Imbens, 2019). Hence, we can modified equation (1) become regression discontinuity version (Imbens and Lemieux, 2008) as follow,

(5) $\ln C_{r t}=\delta_{0}+\delta_{1} \times 1\left(V_{r t}^{\tau}=\beta\right)+\hat{f}\left(V_{r t}^{c}\right)+\hat{g}\left(V_{r t}^{c}\right) \times 1\left(V_{r t}^{\tau}=\beta\right)+\zeta X_{r t}+\eta_{r t}+\epsilon_{r t}$

Equation (4) stated that assessing the effect of spreading of COVID-19 decomposed through coefficient $\delta_{1}$ where the human mobility within containment policy boundaries equal $\beta$. Otherwise, without policy $\beta=$ 0 . The $X_{r t}$ is exogenous variable associated with $R_{r t}, T_{r t}, D_{r s t}$. I decomposed $V_{r t}^{\tau}$ and $V_{r t}^{c}$ as

(6) $V_{r t}^{i}=\left(\begin{array}{c}1 \\ 1\left\{v_{z t}^{i}=\beta\right\} \cdot\left(v_{z t}^{\tau}-v_{z t}^{c}\right) \\ 1\left\{v_{z t}^{i}<\beta\right\} \cdot\left(v_{z t}^{\tau}-v_{z t}^{c}\right)\end{array}\right)$ and $\delta=\left(\begin{array}{c}\delta_{0} \\ \delta_{1}^{\tau} \\ \delta_{1}^{c}\end{array}\right)$

Equation (5) stated that discontinuity of human mobility of $V_{r t}^{\tau}$ within boundaries of $\beta$ will exist by testing parameter $\delta_{1}^{\tau}$ within containment policy boundaries and $\delta_{1}^{c}$ otherwise. We can hold equation 5 still in fixed effect fashion to account for dynamic movement of human mobility within sub district level. We can estimate matrix of $V_{r t}^{i}$ with local regression with triangular kernel to measure greatest weight of regression on the closest center of COVID-19 spread. We can estimate equation (5) with fuzzy regression discontinuity algorithm.

The advantage of equation (5), we can evaluated how containment policy effect on reducing economic agents that represent by human mobility. Whilst other approach such as difference on difference (DID) or instrumental variable (IV) also has similar purpose for evaluating policy impact. Regression discontinuity more closely related to randomized experiment than DID and IV (Imbens and Lemieux, 2008). The regression discontinuity offer relaxed assumption that variable instrument effect on the outcome in casual ways. While I conduct analysis with agent representation within sub district level. This analysis will fit for both empirical or sample test where we can imprecise assess whether containment policy will reduce human mobility due to safety vs economic motives. This analysis in line with the partial lockdown policy motive that enacted by Indonesian government. This policy has lead internal debate whether the policy should strongly consider between economic vs health safety.

In equation (5), we can analyzed how other region can benefit from this policy by estimating spreading impact into specific interaction from COVID-19 center. While I assumed that spatial boundaries within treatment area. The partial lockdown policy that enacted by government still allow human mobility to fulfil basic needs such as food, energy, health, and logistic. The assumption will be different if the policy enacted with fully lockdown (e.g. Wuhan Lockdown) that requires stringent restriction of human mobility and produce greater impact on human restriction mobility. Therefore, we can assess the model by applying 
treatment policy only in particular region without stringent assumption on border separation as noted by Keele and Titiunik (2015).

\section{Data and Method}

I combined three sources of data that is car traffic congestion data, map data, and COVID-19 daily case data. Car congestion traffic obtained from Waze Dashboard Data. This data is not publicly available, we should become a partner to retrieve the data. The Waze provides details information such as hours report (i.e. especially for jam report that consist stand still traffic, heavy traffic, and moderate traffic). In hours report Waze also report car flow of origin and destination to specific destination. While map data was obtain from Indonesian Geospatial Agency with 1.000.000 scale with Earth Mercator projection.

\subsection{Data}

\section{a. COVID-19 Case Data}

I employed confirmed case data according to province level. The reason why I used the data because this data provides consistent data availability in terms of daily frequency at province level across Indonesia. In facts, this is the only data published by government, officially. The development of additional COVID-19 case and spatial spread in Indonesia depicted in Figure 1 - Figure 7.

Figure 3. Confirmed Case of COVID-19 on $15^{\text {th }}$ March 2020
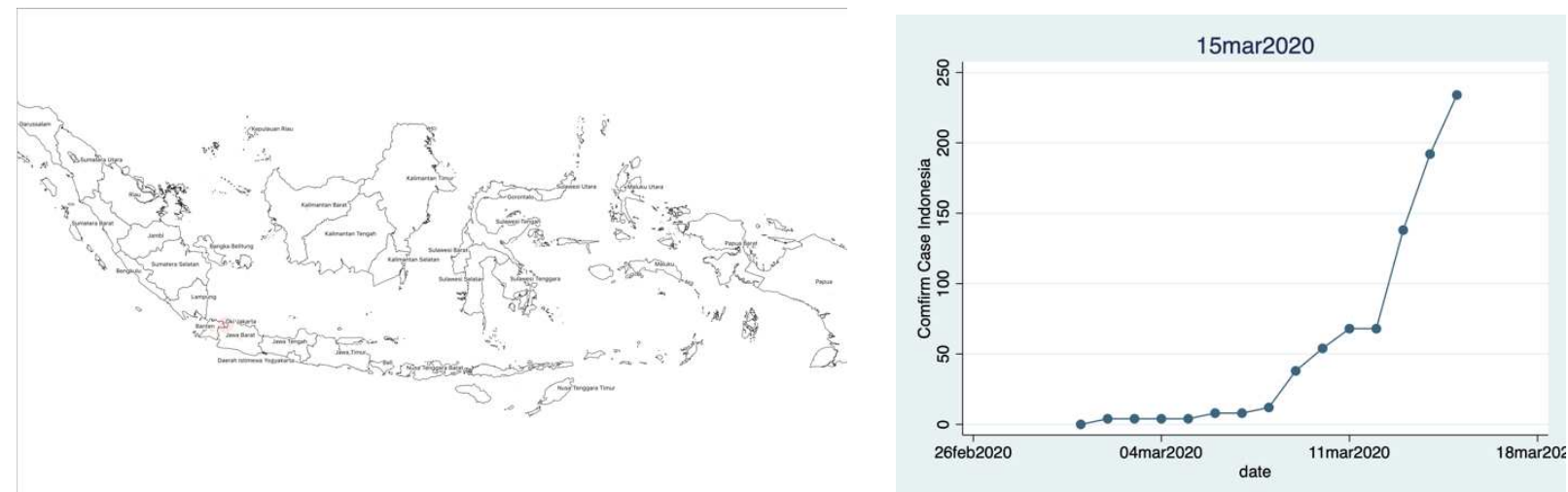

Figure 4. Confirmed Case of COVID-19 on $31^{\text {st }}$ March 2020
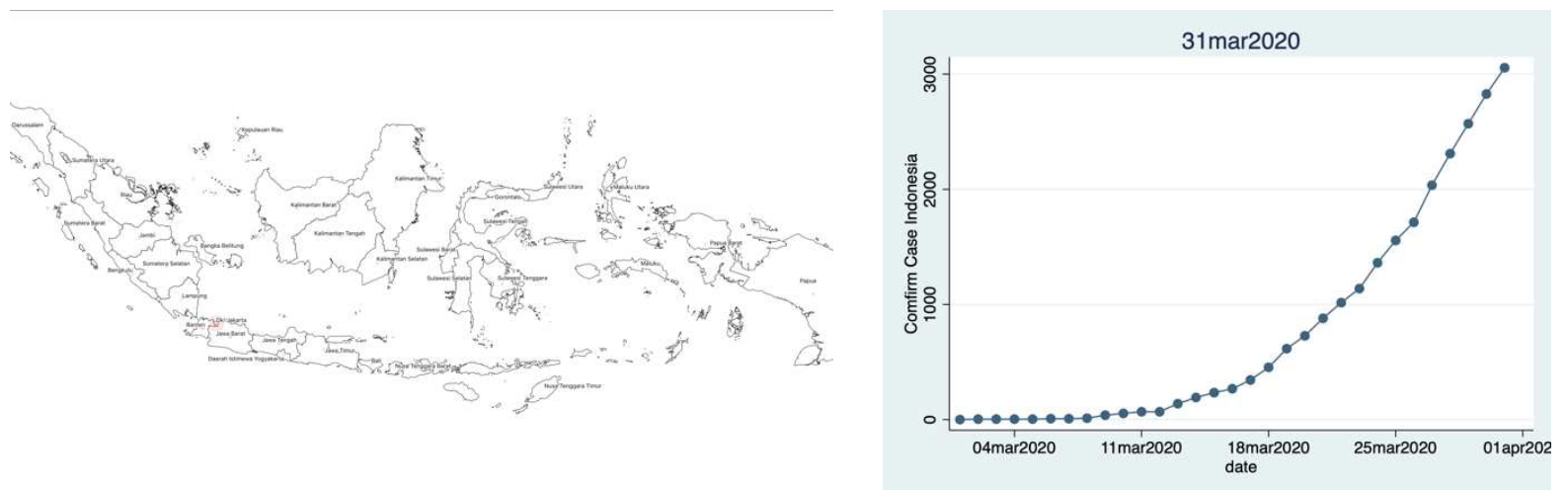

Figure 5. Confirmed Case of COVID-19 on $1^{\text {st }}$ April 2020 

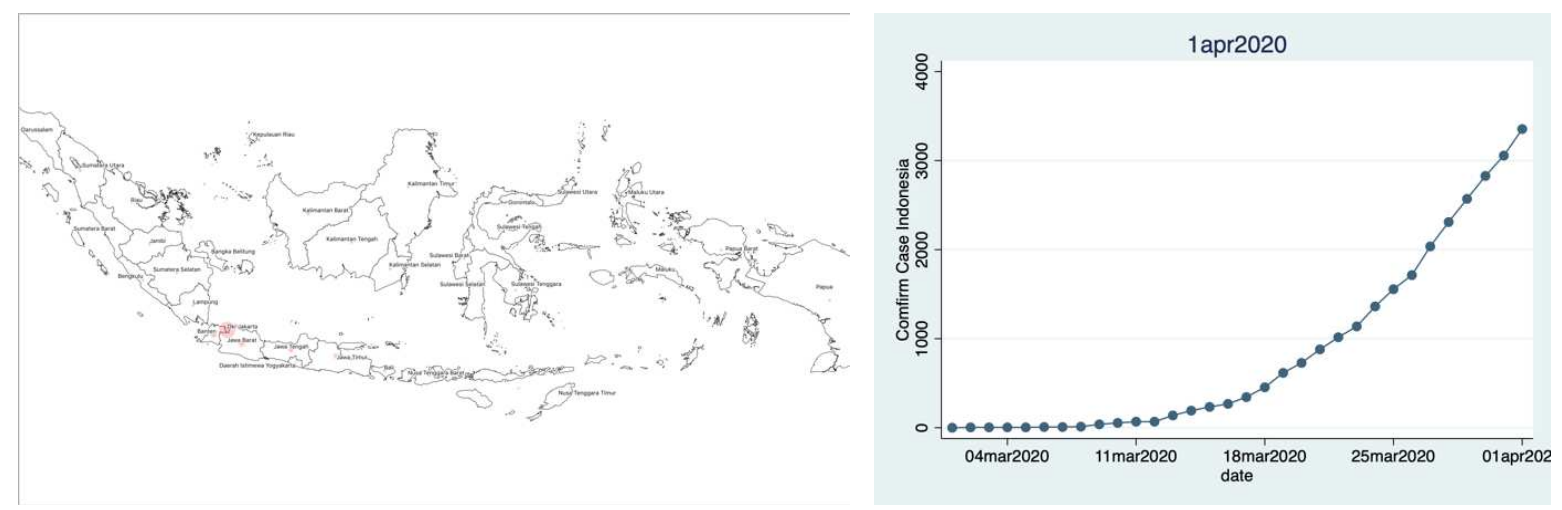

Figure 6. Confirmed Case of COVID-19 on $15^{\text {th }}$ April 2020
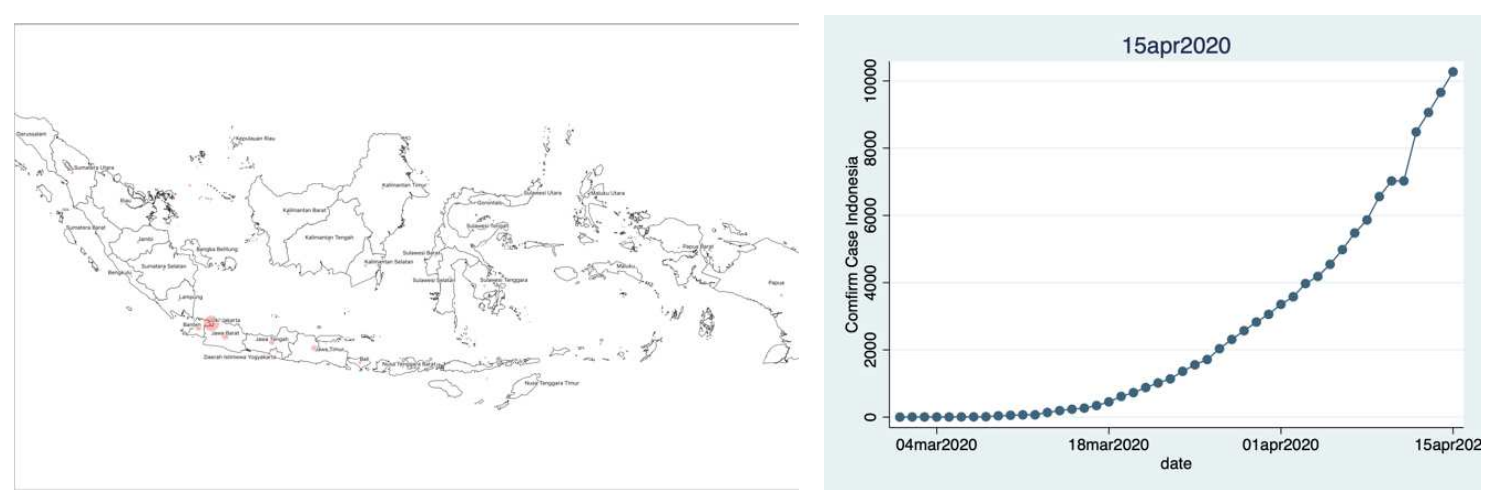

Figure 7. Confirmed Case of COVID-19 on $30^{\text {th }}$ April 2020

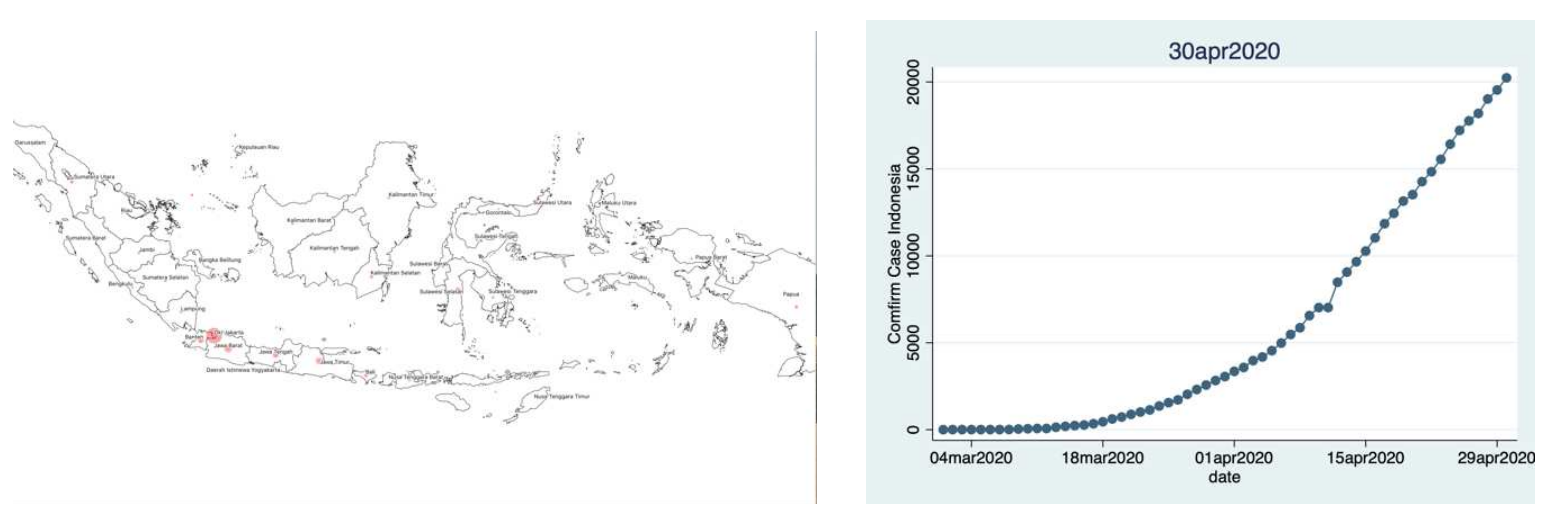



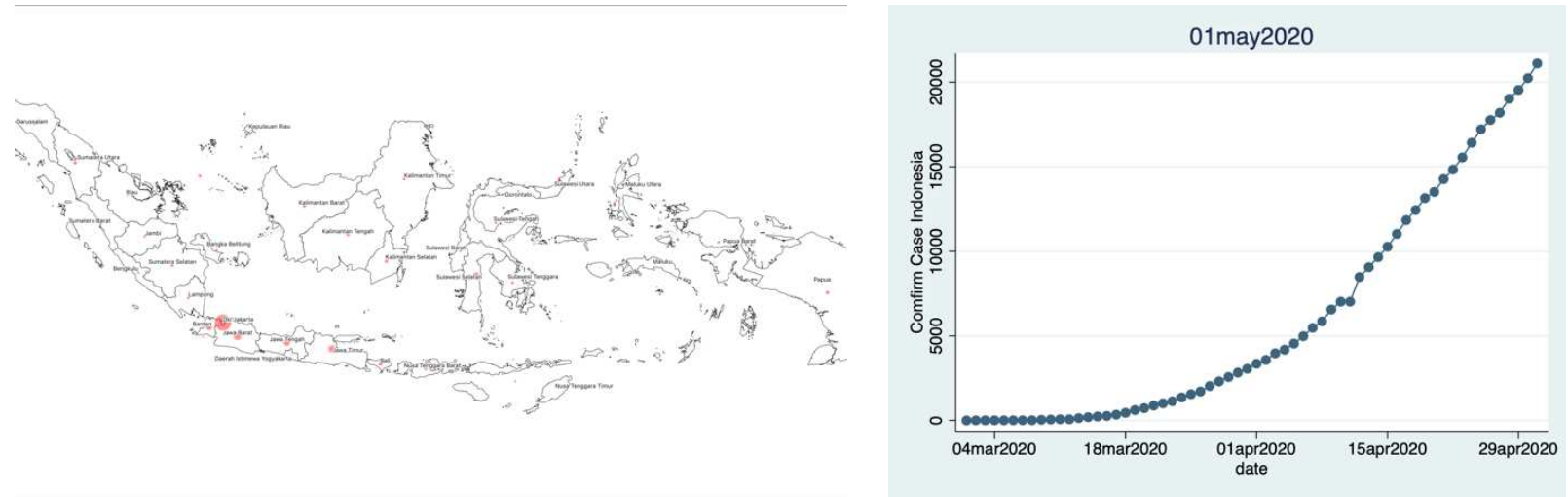

Figure 9. Confirmed Case of COVID-19 on $15^{\text {th }}$ May 2020
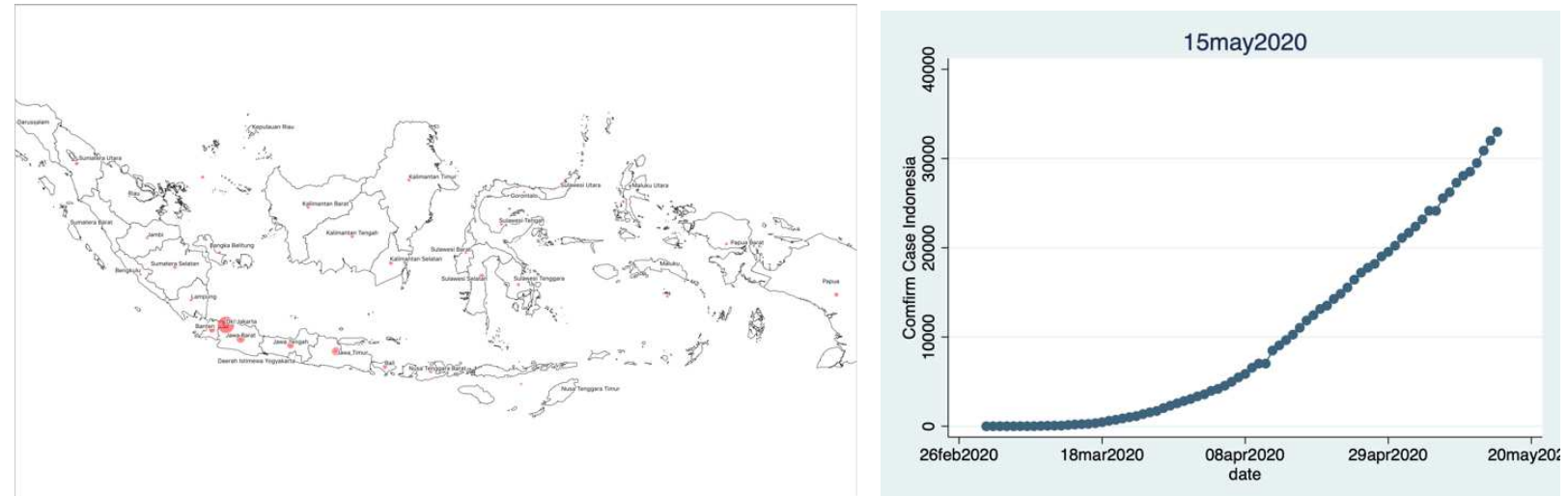

These figures inform us, since in the beginning of March 2020, the first case of COVID-19 confirmed case was in Jakarta and spread across nation especially in Java, Sulawesi and Sumatera. The COVID-19 has increased significantly across region especially in Java Island. This island inhabit by largest population in the country. In Figure 1 - Figure 7, as we can see the illumination of red spot has been increased and darker along with increase the confirmed case of COVID-19 across Java and Indonesia.

\section{b. Human Mobility Data}

Indonesia has 77.254 sub level district within 34 provinces. Each sub level district bounded within administrative boundaries according to government regulation (Ministry of Internal Affair No.137/2017 about The Code and Data of Administrative Boundaries in Local Government) that covered by district within provinces. This administrative boundaries shows how the spatial policy have differences between border because they restricted according to administrative borders.

In order to support spatial mobility across space and time. I mapped human mobility into detail location car congestion mobility within sub district level. I should reduce mobility bias that some of regions such as West Java Province has more mobility than other regions because it crossed by highways. I should calculate, which car on highways will go out, stop and stay in particular regions outside highways mobility. Otherwise, if we estimate the spatial mobility aggregated with larger boundaries such as district, it will increase bias estimation between car congestion and spreading of COVID-19 case. Therefore, it is necessary when the unit analysis has more deeper such as sub level district level. We can map the human mobility across spatial. 
In order to get mobility flow between region, for each observation, I mapped the car GPS location that provides by Waze. So, I can impose on map for hourly report with the GIS software. On other hand, the car located will produce bias interpretation whether they in taxing or stay at the end of the journey. In order to reduce this bias, the data was collected with aggregated daily data to ensure that one region has more consistent flow of car congestion data rather than hourly data.

This method have produced consistent panel data set in time with daily frequency as well as spatial boundaries for each sub level district (called desa) across Indonesia since March 2020 until May 2020. Total mobility data from this method have generated about 6.25 million observations that covered car traffic congestion for each sub level district since at the beginning of March 2020 - May 2020. As we can see in Figure 1 - Figure 3. These figures generated with GIS software where The Waze reported Car Congestion Traffic Report since March 2020 as the beginning of COVID-19 Case in Indonesia towards May 2020 as many of regions have applied PSBB policy. The red dots within map informed us how traffic report event in each sub level district area are enormous across provinces. It seems the luminosity of red spot have reduced to lighter dimmed since April 2020 towards May 2020. Its indicated that car traffic congestion mobility have decreased on May 2020 rather than April 2020.

Figure 10. Car Report Congestion Traffic in Indonesia in March 2020

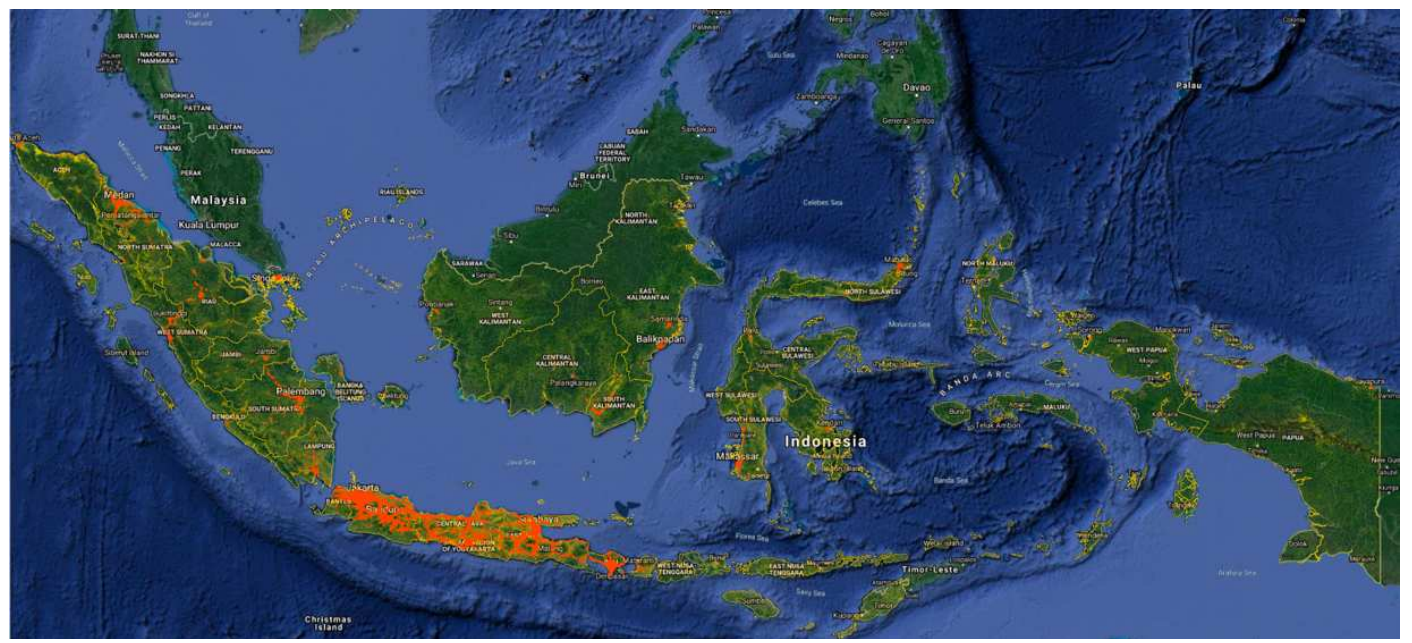




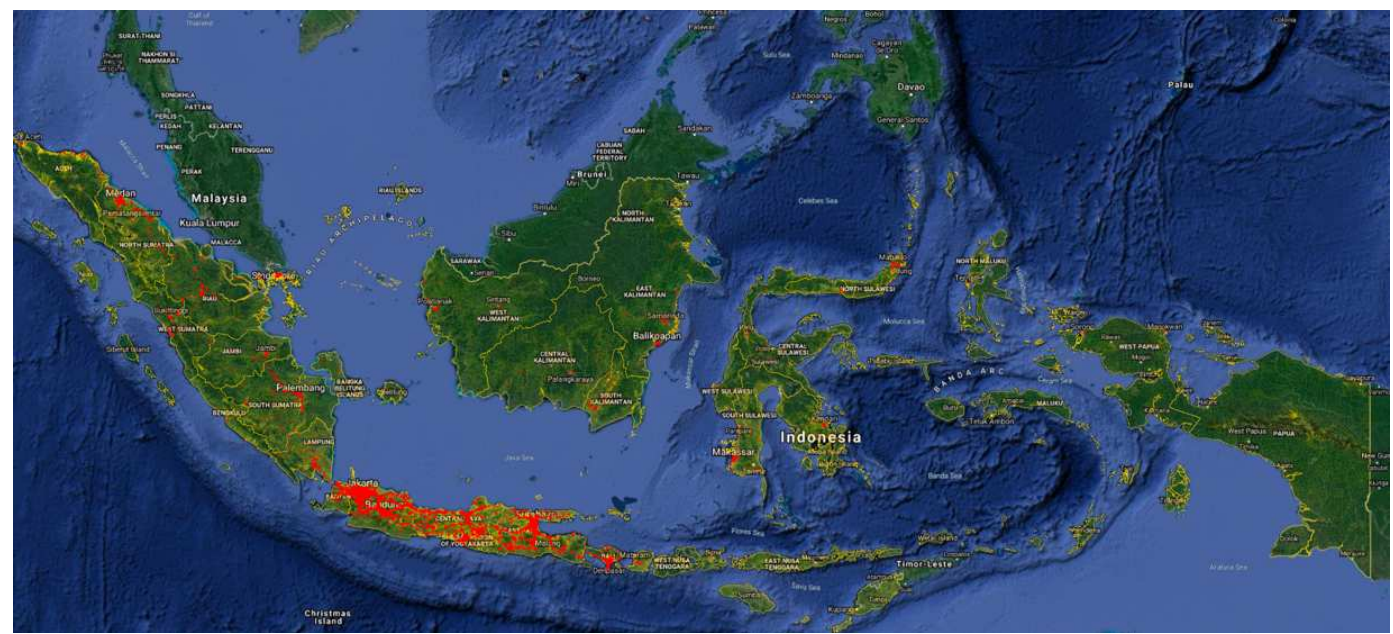

Figure 12. Car Report Congestion Traffic in Indonesia in May 2020

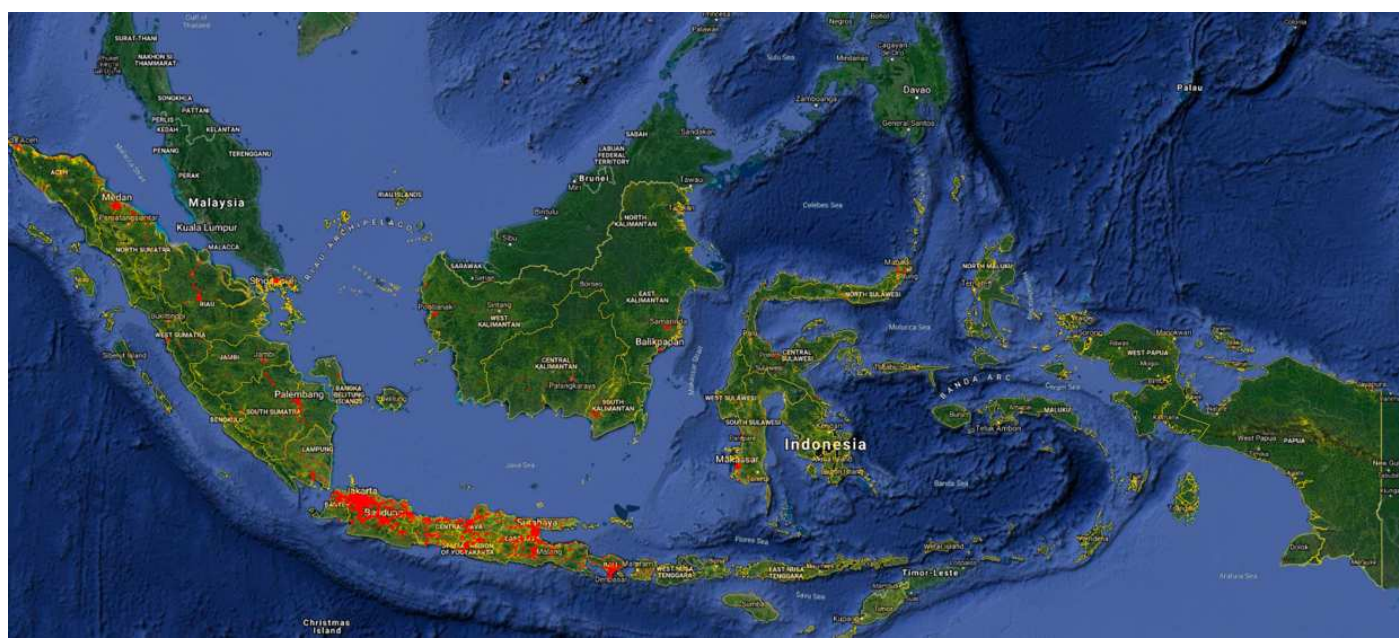

\section{c. Treatment Effect Data}

According to the regulation, Indonesia's containment policy is apply for both province and district level. When one province or district level requires PSBB policy. They should proposed to the Ministry of Health to get a permission whether Central Government permit province or district to conduct PSBB policy. This policy treatment will be estimated according to equation (4) where $T_{r t}$ is time of policy treatment of PSSB in province level or district level. $R_{r t}$ is treatment policy especially for region which conducted PSBB policy whether province or district level.

In addition, another crucial factor that affect on increasing of human mobility is huge culture event that usually stimulate large social gathering. I assessed this time effect policy includes daily effect, weekend effect, and holiday effect to performed seasonal effect of car congestion mobility. These variable will control as unobservable behavior that usually affect on social interaction.

Furthermore, as a major moslem country, Indonesia has a biggest mobility culture in the world. There has been regular culture mobility flow from city to outside city due to Ramadhan or Eid Mubarak across 
province in Indonesia. I apply this effect by performing additional treatment 3 days prior to beginning of Ramadhan and 3 days prior to Eid Mubarak.

Ideally, the containment policy such as noted by Hellewell et al. (2020) will be effective to halt the spread of COVID-19 breaks should be ended in 12 weeks or before 5000 cases in total. The long delay of containment policy will increase probability of increasing transmission of symptom. It's indicates that conducting optimal lockdown policy, in term of effective period and spatial location will reduce spread and controlling of spread COVID-19. Theoretically, the PSBB policy will reduce the spreading of COVID-19 within and surrounding area where outside regions which close to the core produce different outcome.

\subsection{Method}

In order to assess PSBB policy as my first research question. I conducted with two approaches. The first approach that I should assess is whether containment policy has reduced accordingly or not. While my regression discontinuity method focus on geographic border. I prefer using fuzzy regression discontinue method. I concern that measuring the impact through distance parameter requires more one bandwidth selection. I employed triangular kernel to investigates whether distance and mobility along with spreading virus or not. Whether car congestion has a good proxy to depicted of spatial mobility across sub district level.

According to Imbens and Lemieux (2008), I should provide three information to conduct this algorithm. That is demonstrating graph as noted in Figure 1, to measure average outcome over the set of bins of probability of treatment that depicted continuity graph and treatment graph. The test to validate the results conducted with McCrary (2008); (2) computing the ratio in the estimate of jump and the outcome variable with regression results. The standard error should be computed using robust standard error. Choosing optimal bandwidth with cross validation procedure; (3) comparing the results through standard estimates of unconfoundedness.

The second approach is measuring without policy by estimating original equation (1) to estimate whether the case will increase significantly without the containment policy. This estimation is important to measure how actually unreported case actually exist in Indonesia against government report case. This result will be benefit for the decision makers whether the existing report are under report and requires another policy such as applying huge test to estimate real confirm case of COVID-19 or defining optimal economic activity whether the existing policy will be effective to reduce the case and start for economic recovery.

For second research question, whether surrounding region has benefited from this policy. I generated the results from equation (4) by comparing the results of regression discontinuity and its surrounding area of COVID-19 center. It is implausible conducting regression discontinuity approach with spatial boundaries without any point of spatial distance impact.

The estimation will be biased if we combine the analysis. The analysis should be estimate with separate analysis with pair analysis. I focus the containment policy with province level policy rather than district area. I concerned that containment policy enacted in Java regions will increase significantly. Only two provinces have enacted this policy that is DKI Jakarta as the largest confirmed case in Indonesia, and West Java as a hinterland area for DKI Jakarta. For each spatial interaction, I have estimated with pair analysis according to my previous model setup. The steps that I have conducted as follow,

We can elaborate this assumption by analyzing border interaction by conducting estimation between two regions separately that close to treatment region as noted in Figure 2. For instance, when treatment region 
such as Region $\mathrm{X}$ have two neighbors says it $\mathrm{Y}$ and $\mathrm{Z}$. We can estimate the impact by estimating $\mathrm{X} \rightarrow \mathrm{Y}$ and $\mathrm{X} \rightarrow \mathrm{Z}$. These estimation will informed us whether the containment policy more benefit to $\mathrm{Y}$ than $\mathrm{Z}$. Hence, we can predict in which region the case will spread more and enforce containment policy accordingly. For each scenarios we can estimates the impact according to equation (1) by estimating the impact with the following table:

Table 1. Scenario Impact

\begin{tabular}{|l|c|c|c|}
\hline Scenario & PSBB Policy & Impact Region & Impact in percent \\
\hline 1 & DKI-Jakarta & West Java & $\Delta_{\tau}^{1}=\frac{\beta_{\tau}^{1}}{\beta_{c}^{1}}$ \\
\hline 2 & & Banten & $\Delta_{\tau}^{2}=\frac{\beta_{\tau}^{2}}{\beta_{c}^{2}}$ \\
\hline 3 & West Java & DKI-Jakarta & $\Delta_{\tau}^{3}=\frac{\beta_{\tau}^{3}}{\beta_{c}^{3}}$ \\
\hline 4 & & Banten & $\Delta_{\tau}^{4}=\frac{\beta_{\tau}^{4}}{\beta_{c}^{4}}$ \\
\hline 5 & & Central Java & $\Delta_{\tau}^{5}=\frac{\beta_{\tau}^{5}}{\beta_{c}^{5}}$ \\
\hline
\end{tabular}

The results in Table 5, will considered if coefficient in between parameters are significantly according to seemingly unrelated estimation coefficient's $\mathrm{Chi}^{2}$ test.

\section{Results and Discussion}

In this section the result will be align on policy measurement of containment policy (PSBB) and surrounding region effect as well as estimating unreported case in following sub section. Every regression conducted with weighted estimation using kernel triangular procedure and robust standard error. In order to measured closest distance between DKI Jakarta/ West Java and surrounding region. I estimated for each car mobility according to core of sub level district in DKI Jakarta/ West Java and its neighbor with geographic distance. I employ euclidian distance between two of X,Y GPS location. This distance measure become the bandwidth that converted into triangular kernel. I chose the triangle kernel as an optimal bandwidth according to procedure as noted by Imbens and Kalyanaraman (2012). This weight will assist the estimation how human mobility move along the area across spatial. We can evaluate whether human mobility closest to area that portrayed by Car Congestion Report (CR) will reduce the COVID-19 confirmed case.

If we looking at this behavior we can expect that the results with policy or without policy have opposite sign. The baseline estimation will produce positive parameter that indicate without containment policy (there is no restriction policy). Whereas, with policy option there is a significant reduction of Car Congestion Report (CR) hence will decrease the spread of COVID-19 virus.

\subsection{Regression Discontinuity}

In this sub section, the analysis will measure the interaction between geographic boundaries of DKI Jakarta as a center of COVID-19 spread as a first province enact the containment policy. The analysis will be followed with West Java Province as the second province in following days to prevent and support DKI Jakarta containment policy where this region as the closest neighbor with DKI Jakarta. 


\section{a. Containment Policy in DKI Jakarta}

The containment policy in DKI Jakarta started on 10 April 2020. I applied this treatment effect only for DKI Jakarta and it's period accordingly. From this treatment effect, first analysis should measure the impact of this containment policy close to east geographic border that is West Java. Geographically, West Java as a hinterland of DKI Jakarta will have spillover effect on DKI Jakarta. They West Java also has significant number of confirmed case of COVID-19 after DKI Jakarta. Where the capital city of West Java in Bandung located in middle of area of provinces.

In daily basis, the capital city of West Java has been frequently visited by visitors from DKI Jakarta. The travel time from DKI Jakarta to Bandung about 2- 3 hours trips. Every weekend these visitors, usually visit Bandung and overwhelmed this city with heavy traffic. Hence, it is logic when DKI Jakarta region has been contaminated, its spread by the visitor to Bandung as the capital city of West Java and contagious to other region. The West Java have 40-43 million inhabitant alone that indicates as the largest population in Indonesia. While DKI Jakarta has its first case, it followed by West Java Province only in 2-3 weeks.

In fact, in district level West Java have five regions which share borders with DKI Jakarta such as The City of Bogor, District of Bogor, The City of Bekasi, District of Bekasi, and The City of Depok. In Figure 13, as we can see, the baseline graph as a control for both period and group, the human restriction mobility has decreased the confirmed case but along with containment policy in bit increase and still produce continuity results. In the baseline graph its indicated that continuity assumption has been fulfilled. I confirmed the results by conducting McCrary (2008) test continuity the density around the treatment threshold of zero. The test does not reject continuity in the running variable of geographic boundaries threshold.

In addition that the first confirmed case of COVID-19 in Indonesia is on the beginning of March 2020. I put red line at $3^{\text {rd }}$ of March as the first case of COVID-19 confirmed in Indonesia. 
Figure 13. DKI Jakarta - West Java Difference in Difference (DID) Regression Discontinuity

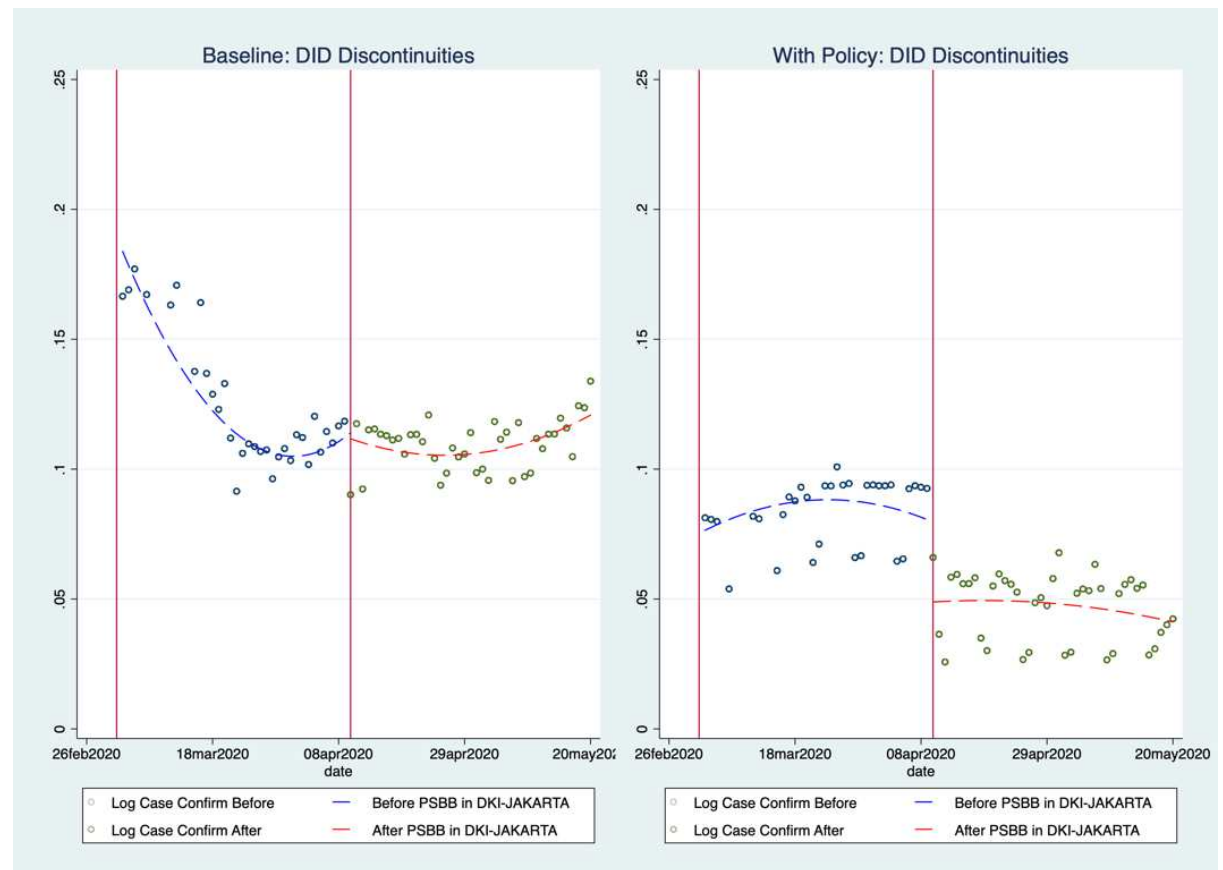

Table 2.Regression Discontinuity for DKI Jakarta - West Java Interaction

\begin{tabular}{lcccccc}
\hline & \multicolumn{2}{c}{ Parameters in Baseline } & \multicolumn{3}{c}{ Parameter in Treatment } \\
VARIABLES & Coefficient & Std Error & P-value & Coefficient & Std Error & P-value \\
\hline Ln(Congestion Report) & $-0.013^{* * *}$ & 0.001 & 0.000 & $0.005^{* * * *}$ & 0.000 & 0.000 \\
Ln(Congestion Report) x Treat & $\mathbf{0 . 0 2 1}$ & $\mathbf{0 . 0 2 9}$ & $\mathbf{0 . 4 6 3}$ & $\mathbf{- 0 . 0 3 1} * * *$ & $\mathbf{0 . 0 0 1}$ & $\mathbf{0 . 0 0 0}$ \\
Weekend & $0.059^{* * *}$ & 0.003 & 0.000 & $0.029^{* * *}$ & 0.001 & 0.000 \\
Holiday & $-0.017^{* * *}$ & 0.006 & 0.004 & 0.000 & 0.003 & 0.924 \\
Beg. Ramadhan & - & - & - & $0.012^{* * *}$ & 0.002 & 0.000 \\
Ied Mubarak & - & - & - & $0.018^{* * *}$ & 0.002 & 0.000 \\
Observations & 18,733 & & & 18,733 & & \\
R-squared & 0.236 & & & 0.290 & & \\
Control Var. & Yes & & & & & \\
\hline
\end{tabular}

$* * * \mathrm{p}<0.01, * * \mathrm{p}<0.05,{ }^{*} \mathrm{p}<0.1$, This regression includes city fixed effects and clustered standard errors at sub level district space and time level

In order to confirmed results of Figure 13, I reported that regression results of the graph in Table 2 represent as a character. I conducted control estimation in baseline period with estimating unobserved fixed effect model to take out the control effect in control group model as noted by Wooldridge (2016). When we take this control effect. We can find out similar parameter of Car Congestion Report (CR) on control observation without treatment effect. The idea why I separated this variable, because we have to measure that control group will not change the treatment effect hence we can fulfill continuity assumptions.

In panel of With Policy option in Figure 13, the DID discontinuity graph indicates there is a significant decreases of Car Congestion Report has reduce the COVID-19 spread. Its depicted, that with PSBB policy reduce COVID-19 spread. If we test the parameter on $\operatorname{Ln}(\mathrm{CR})$ in Baseline and $\operatorname{Ln}(\mathrm{CR})$ in With Policy. The seemingly inrelated estimation coefficient has different significantly with $\mathrm{Chi}^{2}$ test $(\mathrm{p}=0.000)$.

After we test these parameters ( $\operatorname{Ln}($ Congestion Report) $x$ Treat), we compare the results by estimating 
equation (1) that $\Delta_{\tau}^{1}=\frac{0.021}{-0.031} \cdot 100=-67.74 \%$. It's indicates that containment policy in PSBB has effect on decreasing confirmed case about $67.92 \%$. We can says that containment policy in this regions has been significantly reduce spreading COVID-19 effectively about $67.74 \%$.

Although the parameter such as weekend, and the beginning of Ramadhan and end of Ramadhan or we called as Ied Mubarak. The containment policy that conducted in DKI Jakarta is effectively prevent COVID-19 spread in DKI Jakarta alone but its neighbor simultaneously. The preventive treatment that conducted by The Governor of DKI Jakarta, Anies Baswedan has been praised for his preventive action to enact this policy immediately even since in the middle of March ${ }^{5}$. The governor's response has been precautious to conduct this policy as soon as possible, where he responsible for the largest metropolitan region inhabitant and capital city of Indonesia. He concerned that this policy will impact to other region especially her close neighbor such as West Java and Banten Province.

\section{Figure 14. DKI Jakarta - Banten Difference in Difference (DID) Regression Discontinuity}

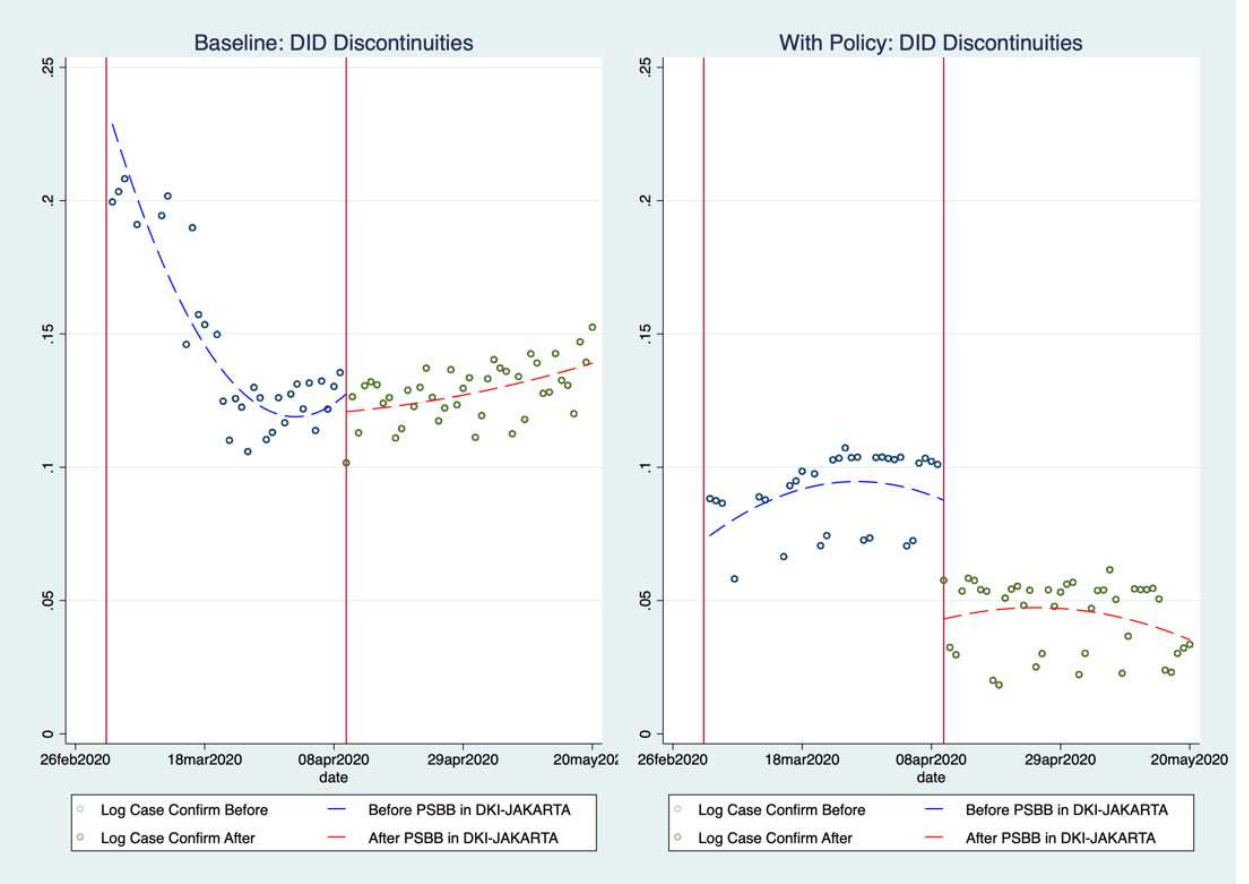

If we compare the results with other close region that is Banten Province. The results indicates in Figure 14 as well as estimation results in Table 3. After I passed continuity test according to McCrary (2008). The parameters impact has different results as depicted in Table 3. After I tested with seemingly inrelated estimation coefficient. The parameters that I tested that is $\operatorname{Ln}$ (Congestion Report) $\mathrm{x}$ Treat. The parameter from the baseline has reduced into $-70.96 \%$ due to containment policy impact. The human restriction mobility has decreased significantly about $70.96 \%$ on spreading COVID-19 across DKI Jakarta - Banten Province boundaries.

The impact of exiting policy has higher results on Banten compare to West Java Province. Why Banten Province has higher impact rather than West Java impact, because if we looking at the area and population inhabitant. Most of urban area in Banten has closer interaction with DKI Jakarta. The City of Tangerang,

\footnotetext{
${ }^{5}$ https://www.thejakartapost.com/news/2020/03/20/covid-19-anies-urges-jakartans-to-avoid-traveling-outside-thecity-for-three-weeks.html
} 
District of Tangerang and The City of South Tangerang smaller amount of human mobility interaction with DKI Jakarta rather than West Java Province in terms number of cities and districts. The containment policy in DKI Jakarta reduce more effectively 3\% higher in Banten Province than West Java Province. During this study these cities were not enacted yet the containment policy.

\section{Table 3. Regression Discontinuity for DKI Jakarta - Banten Interaction}

\begin{tabular}{lcccccc}
\hline & Parameters in Baseline & \multicolumn{4}{c}{ Parameter in Treatment } \\
VARIABLES & Coefficient & Std Error & P-value & Coefficient & Std Error & P-value \\
\hline Ln(Congestion Report ) & $-0.014^{* * *}$ & 0.001 & 0.000 & $0.005^{* * *}$ & 0.000 & 0.000 \\
Ln(Congestion Report) x Treat & $\mathbf{0 . 0 2 2}$ & $\mathbf{0 . 0 3 0}$ & $\mathbf{0 . 4 4 6}$ & $\mathbf{- 0 . 0 3 1 * * *}$ & $\mathbf{0 . 0 0 1}$ & $\mathbf{0 . 0 0 0}$ \\
Weekend & $0.069^{* * *}$ & 0.003 & 0.000 & $0.031^{* * *}$ & 0.001 & 0.000 \\
Holiday & -0.007 & 0.008 & 0.381 & $0.009^{* *}$ & 0.003 & 0.014 \\
Beg. Ramadhan & - & - & - & $0.017^{* * *}$ & 0.003 & 0.000 \\
End. Ramadhan & - & - & - & $0.022^{* * *}$ & 0.002 & 0.000 \\
Observations & 13,237 & & & 13,237 & & \\
R-squared & 0.243 & & & 0.328 & & \\
Control Var. & Yes & & &
\end{tabular}

\section{b. Containment Policy in West Java Province}

West Java Province enacted the containment policy in 15 April 2020. Only seven days after DKI Jakarta applied this policy. While West Java has largest population in Indonesia and largest area of containment policy. The results will be less effective due to its wide area and law enforcement officer to ensure that this policy will be works effectively.

On the other hand, the Governor of West Java stated that this policy will support existing containment policy in DKI Jakarta and reduce significant spread of COVID-19. The containment policy started with close border areas with DKI Jakarta and followed with The City Bandung as the capital city of West Java. This policy was enacted within 7 days later that is 22 April 2020. While my scenario supported with province level data rather than district data. The treatment policy in province level I started with 15 April 2020 as the beginning of containment policy in West Java rather than 22 April 2020.

In order to conduct this analysis, I changed the core of COVID-19 spread within The City of Bandung. So we changed the distance bandwidth and triangular kernel accordingly as a regression weight in the panel fixed effect model. The result demonstrates in Figure 15 as well as Table 4 for regression results. The first step is conducting continuity test according to McCrary (2008) test. After I passed this test. The results in Table 4 (Ln(Congestion Report) $x$ Treat) confirm that with policy option the results has lowered the spread case of COVID-19 rather than baseline.

I test for both parameters ( $\operatorname{Ln}($ Congestion Report) $\mathrm{x}$ Treat) baseline and with policy with unrelated seemingly regression that indicates significant differences between two parameters. Hence we calculated the impact by estimating parameter in the baseline and treatment coefficient that is $(0.010 /-0.016) * 100=$ $62.51 \%$. This means that containment policy in West Java Province has decreased $62.51 \%$ towards DKI Jakarta. If we compare the results between DKI-Jakarta interaction to West Java - DKI Jakarta interaction. The interaction impact from DKI-Jakarta is larger than West Java impact. This means that controlling 
COVID-19 spread more effectively from the core as soon as possible. While the containment policy enacted by the following region such as West Java which conducted specific region which share border with DKI Jakarta effectively reduce the human restriction as well as spread of COVID-19 in the rest of West Java region such as The City of Bandung.

\section{Figure 15. West Java - DKI Jakarta Difference in Difference (DID) Regression Discontinuity}

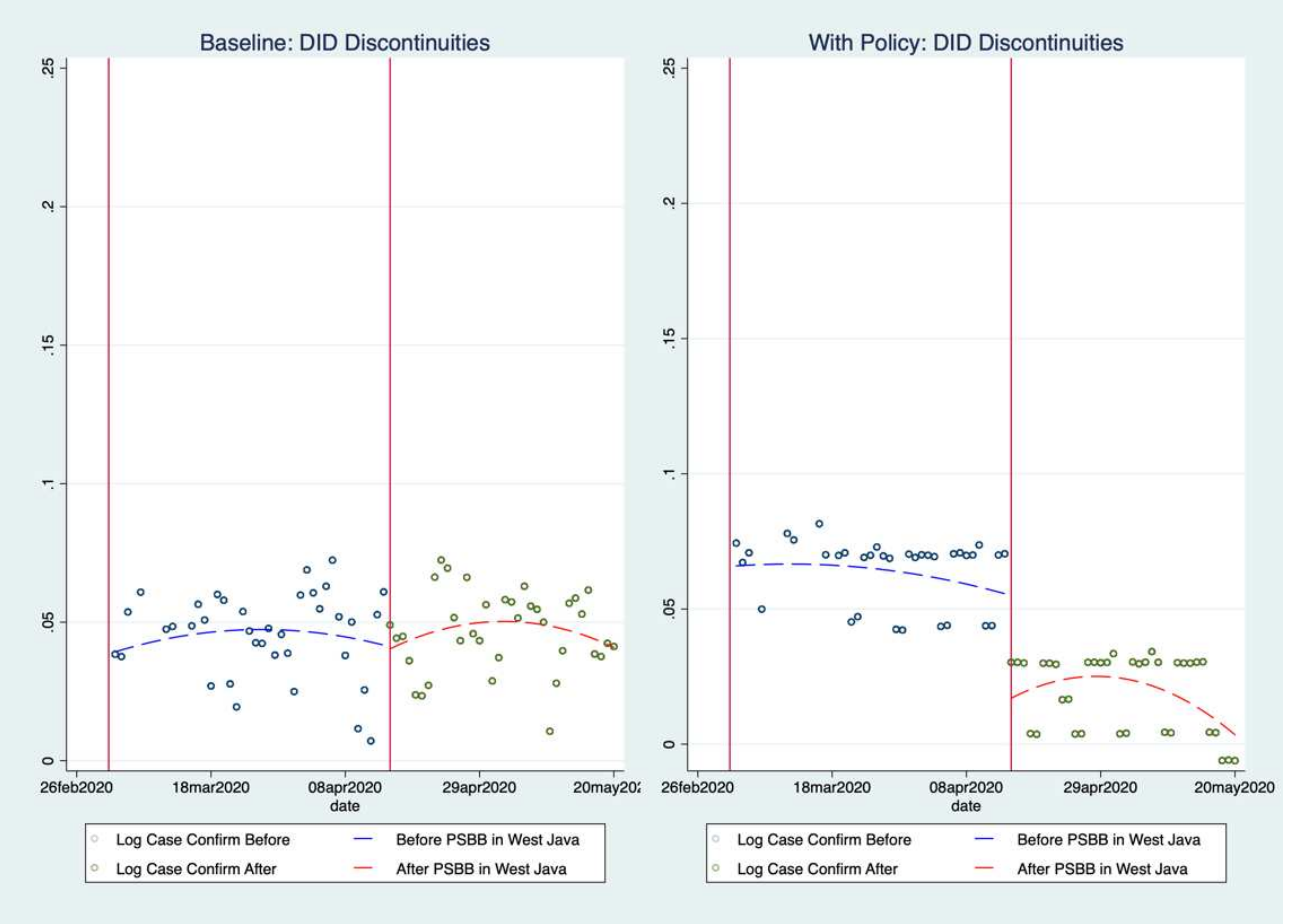

Table 4. Regression Discontinuity for West Java-DKI Jakarta Interaction

\begin{tabular}{|c|c|c|c|c|c|c|}
\hline \multirow[b]{2}{*}{ VARIABLES } & \multicolumn{3}{|c|}{ Parameters in Baseline } & \multicolumn{3}{|c|}{ Parameter in Treatment } \\
\hline & Coefficient & Std Error & P-value & Coefficient & Std Error & P-value \\
\hline Ln(Congestion Report) & $-0.009 * * *$ & 0.001 & 0.000 & $0.007 * * *$ & 0.000 & 0.000 \\
\hline Ln(Congestion Report) $x$ Treat & 0.010 & 0.011 & 0.390 & $-0.016 * * *$ & 0.001 & 0.000 \\
\hline Weekend & $0.050 * * *$ & 0.002 & 0.000 & $0.026 * * *$ & 0.001 & 0.000 \\
\hline Holiday & 0.006 & 0.005 & 0.261 & $-0.006^{* *}$ & 0.003 & 0.045 \\
\hline Beg. Ramadhan & - & - & - & $0.017 * * *$ & 0.003 & 0.000 \\
\hline End. Ramadhan & - & - & - & $0.038 * * *$ & 0.002 & 0.000 \\
\hline Observations & 18,733 & & & 18,733 & & \\
\hline R-squared & 0.205 & & & 0.196 & & \\
\hline Control Var. & Yes & & & & & \\
\hline
\end{tabular}

If we compared the West Java - DKI Jakarta interaction results with West Java - Banten interaction as demonstrates in Figure 16 and Table 5 for regression estimation. After I completed continuity test. The results indicates that only decreases about $-1.872 \%((0.00038 /-0.0204) \times 100=-1.872 \%)$. It is confirmed with my previous statement where the containment policy will work accordingly if the government policy can ensure the human restriction mobility effectively cover the area. If the government can not ensure in terms 
of scope and area to restrict human mobility. The policy will not work effectively. The policy should be effectively in line with law enforcement and assure that human restriction is persistently exist during the treatment period.

\section{Figure 16. West Java - Banten Difference in Difference (DID) Regression Discontinuity}
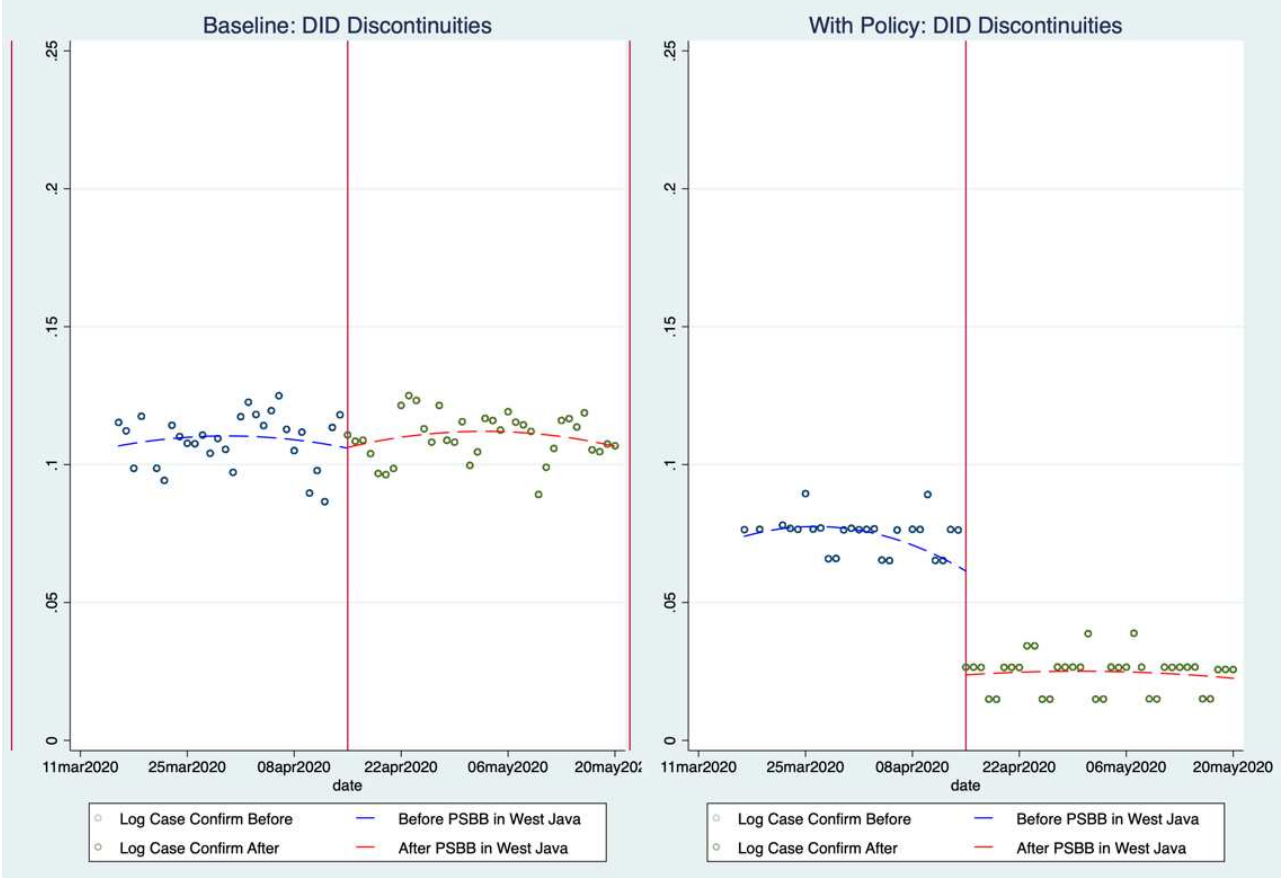

Table 5. Regression Discontinuity for West Java - Banten Interaction

\begin{tabular}{lcccccc}
\hline & \multicolumn{2}{c}{ Parameters in Baseline } & \multicolumn{4}{c}{ Parameter in Treatment } \\
VARIABLES & Coefficient & Std Error & P-value & Coefficient & Std Error & P-value \\
\hline Ln(Congestion Report) & $0.003^{* *}$ & 0.002 & 0.042 & $0.009^{* * *}$ & 0.001 & 0.000 \\
Ln(Congestion Report) x Treat & $\mathbf{0 . 0 0 1 6}$ & $\mathbf{0 . 0 0 8}$ & $\mathbf{0 . 9 6 3}$ & $\mathbf{- 0 . 0 2 0} * * *$ & $\mathbf{0 . 0 0 1}$ & $\mathbf{0 . 0 0 0}$ \\
Weekend & -0.001 & 0.003 & 0.725 & $0.013^{* * *}$ & 0.001 & 0.000 \\
Holiday & $-0.019 * * *$ & 0.005 & 0.000 & $-0.018^{* * *}$ & 0.003 & 0.000 \\
Beg. Ramadhan & - & - & - & -0.001 & 0.002 & 0.648 \\
Ied Mubarak & - & - & - & $0.005^{* * *}$ & 0.002 & 0.002 \\
Observations & 13,130 & & & 13,130 & & \\
R-squared & 0.261 & & & 0.223 & & \\
Control Var. & Yes & & & & & \\
\hline
\end{tabular}

${ }^{* * *} \mathrm{p}<0.01, * * \mathrm{p}<0.05, * \mathrm{p}<0.1$, This regression includes city fixed effects and clustered standard errors at sub level district space and time level

In the last analysis of Difference in Difference Regression Discontinuity for interaction between West Java and Central Java. The results demonstrated in Figure 17 and Table 6. After I passed the McCrary, (2008) continuity test. The impact estimation between two parameters of Table 5 parameters of $(\operatorname{Ln}($ Congestion Report) $\mathrm{x}$ Treat) for baseline compared to treatment by testing with seemingly unrelated estimation. It is stated that impact has reduced about $-6.903 \%$. 


\section{Figure 17. West Java - Central Java Difference in Difference (DID) Regression Discontinuity}

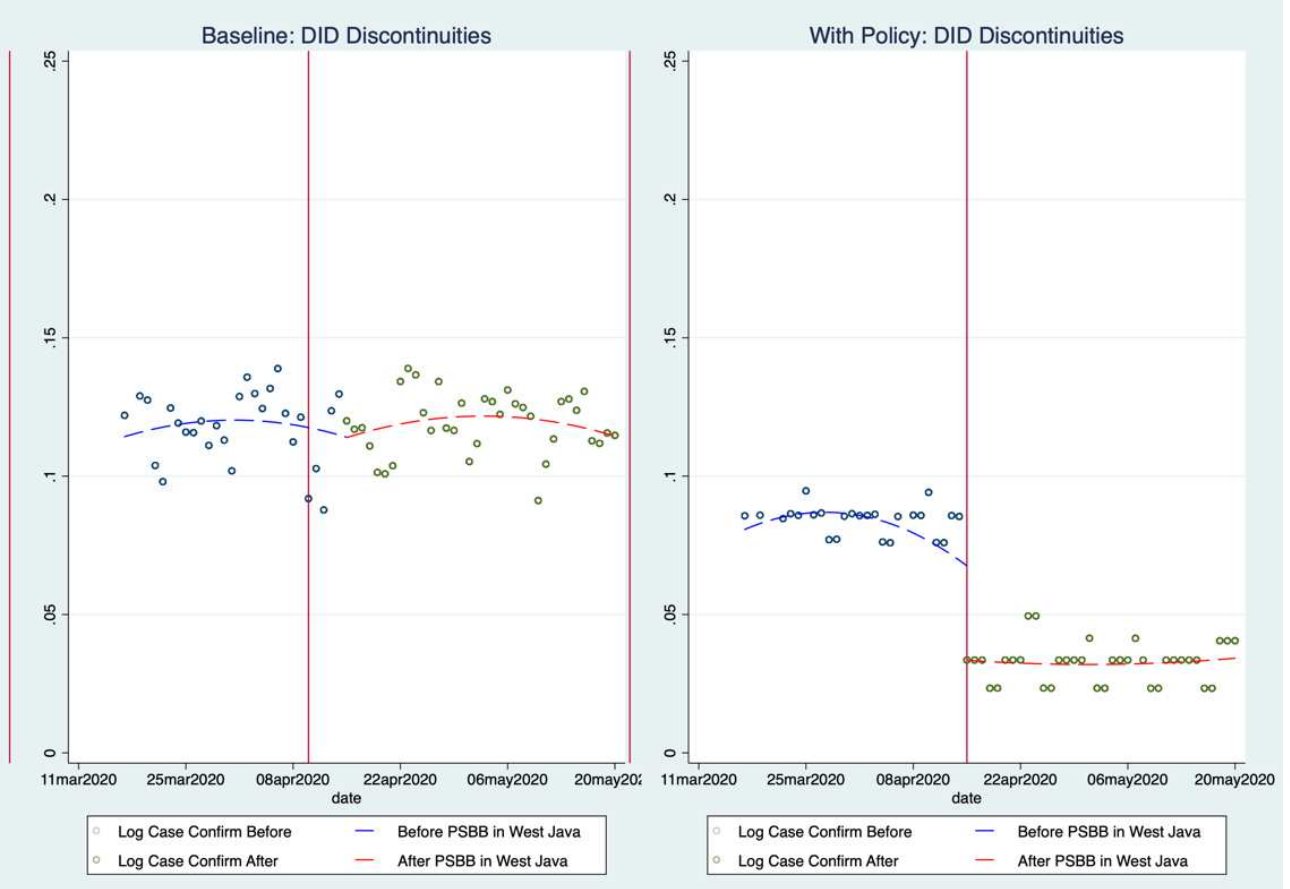

Table 6. Regression Discontinuity for West Java - Central Java Interaction

\begin{tabular}{|c|c|c|c|c|c|c|}
\hline \multirow[b]{2}{*}{ VARIABLES } & \multicolumn{2}{|c|}{ Parameters in Baseline } & \multicolumn{4}{|c|}{ Parameter in Treatment } \\
\hline & Coefficient & Std Error & P-value & Coefficient & Std Error & P-value \\
\hline Ln(Congestion Report) & 0.001 & 0.002 & 0.416 & $*$ & 01 & 0.000 \\
\hline Ln(Congestion Re & 0.002 & 0.008 & 39 & -0.0 & 0.001 & 0.000 \\
\hline Weekend & -0.003 & 0.004 & 0.378 & 0.0 & 0.002 & 0.000 \\
\hline Holiday & $-0.016 * * *$ & 0.005 & 0.003 & 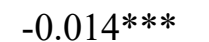 & 0.003 & 0.000 \\
\hline han & - & - & . & -0. & 0.003 & 0.003 \\
\hline & - & - & & & 0.002 & 0.284 \\
\hline Obs & 10,849 & & & 10,849 & & \\
\hline R-sq & 0.292 & & & 0.246 & & \\
\hline Control Var. & Yes & & & & & \\
\hline \multicolumn{7}{|c|}{$\begin{array}{l}* * * \mathrm{p}<0.01, * * \mathrm{*}<0.05, * \mathrm{p}<0.1, \text { This regression includes city fixed effects and clustered standard errors at sub level district space } \\
\text { and time level }\end{array}$} \\
\hline \multicolumn{7}{|c|}{$\begin{array}{l}\text { Table } 6 \text { confirmed with previous results, that the containment policy that conducted partial lockdown style } \\
\text { in Indonesia only works with limited scope and control area. This policy will effectively reduce spread of } \\
\text { COVID-19 virus if the policy conducted in immediate response. The multi layer of containment policy as } \\
\text { conducted by DKI Jakarta and West Java will reduce effectively the spread of COVID-19 from the center. } \\
\text { On the other hand, when this policy getting far from the distance the impact is smaller than in the core area. }\end{array}$} \\
\hline $\begin{array}{l}\text { nother information that we sho } \\
\text { gainst containment policy. This } \\
\text { f containment policy. These }\end{array}$ & $\begin{array}{l}\text { Investigat } \\
\text { lavior ind } \\
\text { ble such }\end{array}$ & $\begin{array}{l}\text { ummy } \\
\text { as uno } \\
\text { eekend }\end{array}$ & ion $\mathrm{t}$ & eflect the & & opl \\
\hline
\end{tabular}


policy in DKI Jakarta, the peoples are not aware with the policy. Especially during weekend period, beginning, and prior to Ied Mubarak. People still commute to go out from DKI Jakarta towards West Java, which means the existing of containment policy still unable to hold people stay in their house. On the other hand, in the second scenario the impact of containment policy in DKI Jakarta towards Banten Province in Table 3 have decreased during holiday but still increase during weekend, beginning of Ramadhan and end of Ramadhan.

In addition, the containment policy in West Java and DKI Jakarta has reduce human mobility during holiday but still increase in the weekend and prior to Ied Mubarak according to Table 4 . Whereas in Banten Province side, there is decreasing during holiday and beginning of Ramadhan as demonstrated in Table 5. In Table 6 , there is a significant movement during weekend but reducing human mobility during holiday and beginning of Ramadhan than baseline.

If we compare from those tables. The containment policy produce various impact on reducing human restriction mobility. The containment policy unable to reduce human restriction policy especially during weekend. Although some region has aware to stay at home, on the other hand the people in urban area such as DKI Jakarta the Car Congestion Report sill exist and increase the spreading of COVID-19 confirmed case.

\subsection{Neighbor Impact}

In this subsection, we address the second issue of paper objective about impact of containment policy on the neighbor region. This analysis will confirm the previous result by depicting the results along with distance effect. I depicted this results by following the procedure of Imbens and Lemieux (2008). This graph demonstrates us how the geographic boundary will reduce COVID-19 spread.

Figure 18. DKI Jakarta - West Java neighbor impact

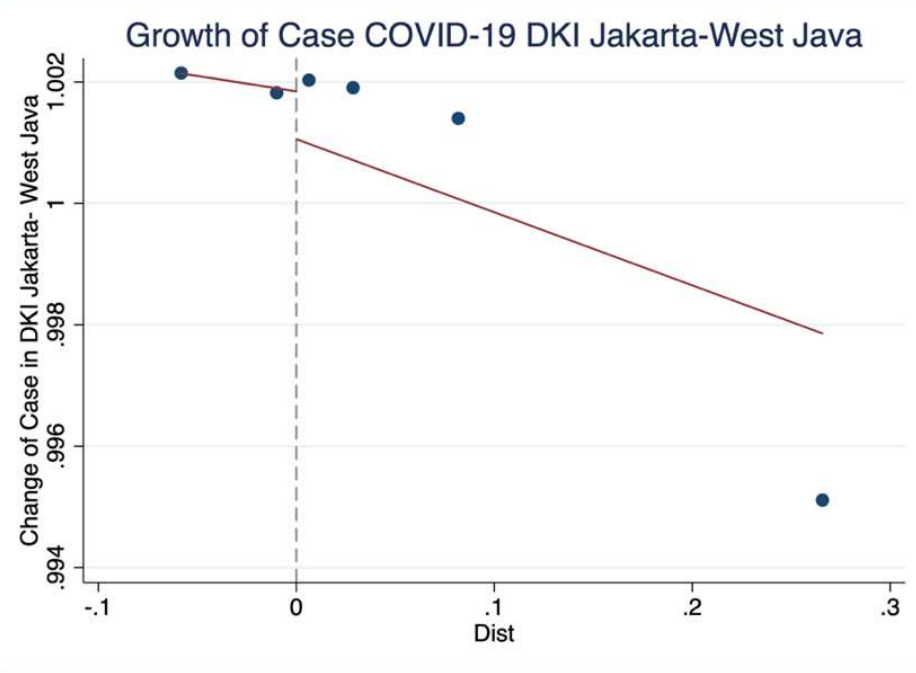


Figure 19. DKI Jakarta - Banten neighbor impact

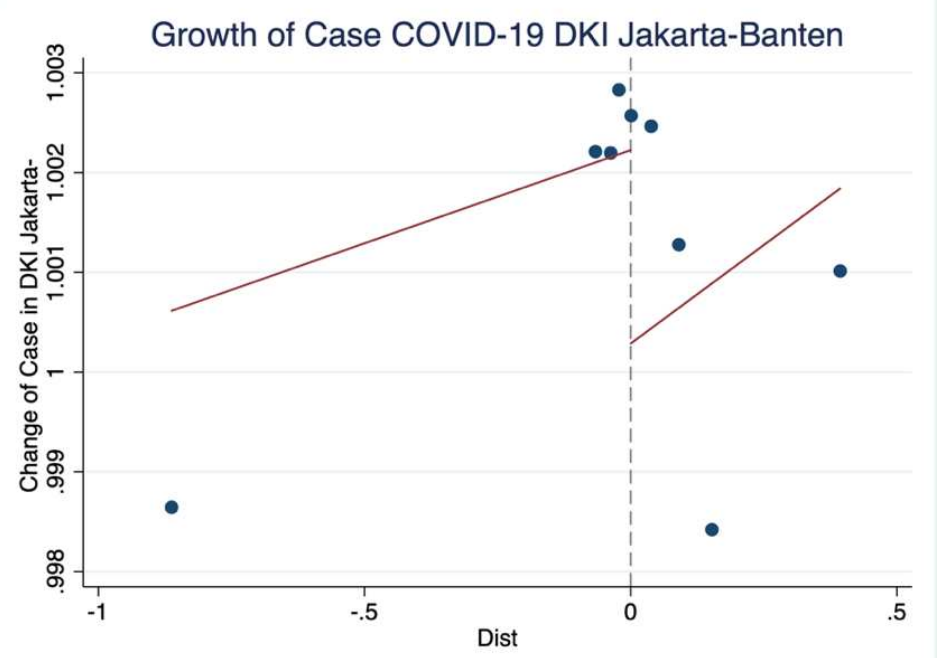

I depicted the results for each results in Figure 18 - Figure 22. Imbens and Lemieux (2008) called this graph as bin graph of regression discontinuity. As we can see in Figure 19. The zero line with red dash line at 0 point is the boundaries cut off or threshold impact between two regions. The expected results should indicates between two areas proved a jump between threshold.

The left side from threshold line indicates impact within boundaries of DKI Jakarta. Whereas in rights side of threshold indicates impact on West Java side. Figure 18 depicted the impact of containment policy in DKI Jakarta impact on West Java. The graph indicates there is a significant jump with decreasing trend along with far distance. There is a significant jump from left side to right side as noted by previous results in DID Discontinuity Graph and Regression Discontinuity Estimation.

In Figure 19, the surrounding region between DKI Jakarta and Banten Province has been decrease. On the other hand, along with further distance from the core the spread of COVID-19 is increased due to increasing of human mobility. In Figure 20 - Figure 22, the graphs indicates how containment policy between West Java Province and others neighbor affect along with geographic boundaries. In Figure 20 the results similar to Figure 18 but much smaller impact as noted in Table 2 and Table 4 . The impact larger between DKI Jakarta - West Java compare to West Java - DKI Jakarta as I noted earlier. In Figure 21 the effect of additional confirm case of COVID-19 is much larger than within boundaries. Which means that the containment policy has restricted human mobility within area rather than it surrounding. Although the policy is less effective rather than DKI Jakarta this finding support my previous statement about the control area of policy should be effectively conduct with strong law enforcement act. While the area is getting larger. The policy become ineffective and only works for specific region with smaller area with strong law enforcement act. 
Figure 20. West Java-DKI Jakarta neighbor impact

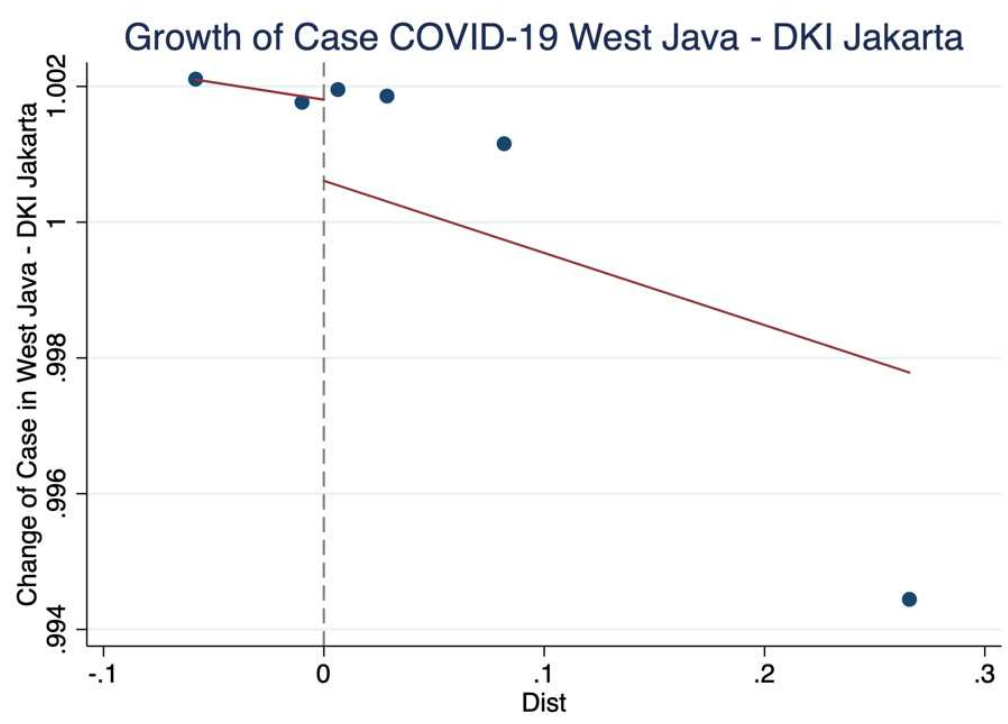

Figure 21. West Java-Banten neighbor impact

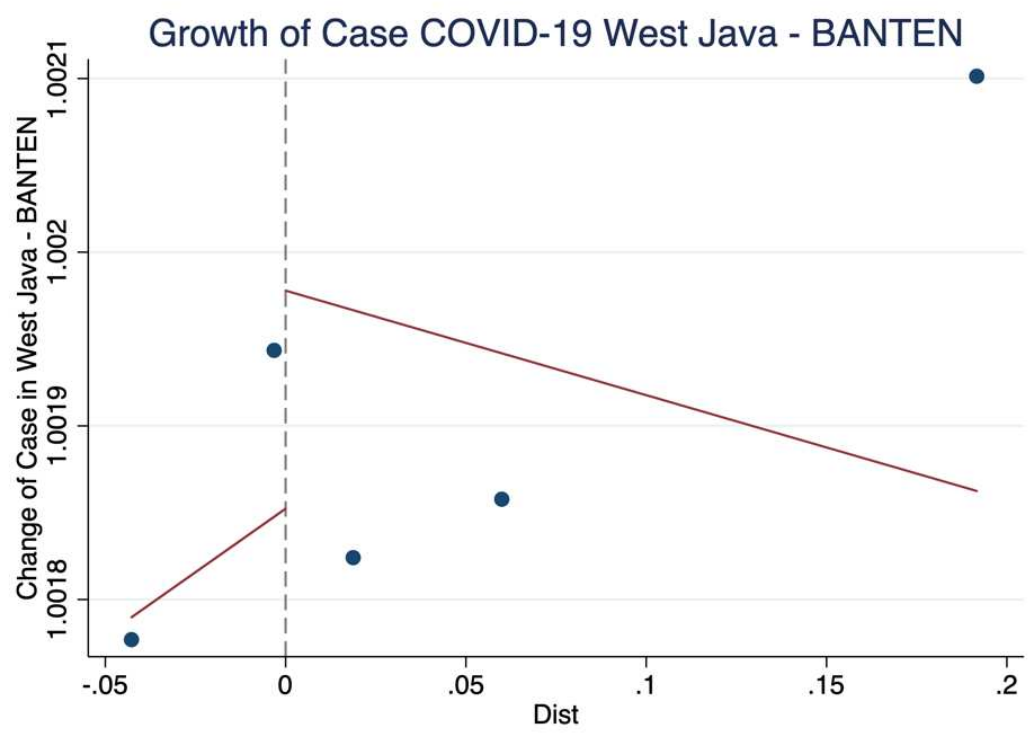


Figure 22. West Java - Central Java neighbor impact

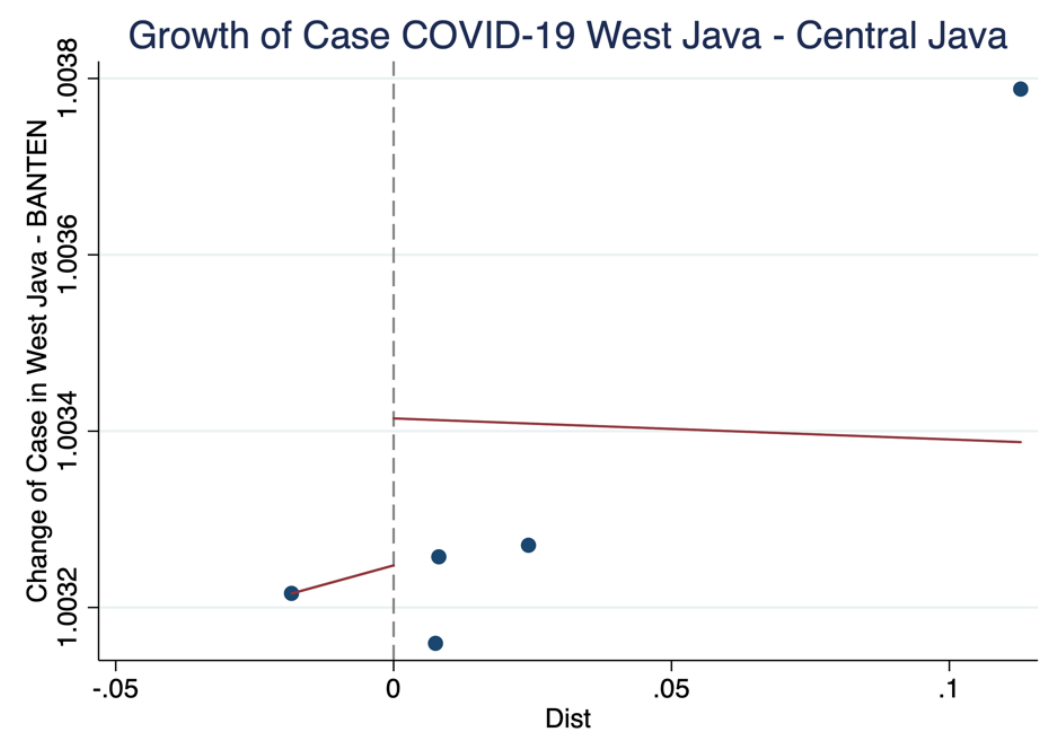

\subsection{PSBB Policy Impact on Indonesia}

In this sub section, I estimated the impact by employing equation (2) with focus on DKI Jakarta's and West Java's Containment Policy on Indonesia's. I followed Hsiang et al., (2020) procedure to assess with and without policy option through equation (2). In without policy option I omitted the treatment variable and forecasted with equation (2). On other hand, with policy option I estimated equation (2) to predict unreported case. The results then compare to observed daily case whether the model can predict as I expected for unreported case.

The results are depicted in Figure 23 and Figure 24. While, the predicted results of unreported cases present in Table 7 and Table 8. In Figure 23, the containment policy in DKI Jakarta has effectively reduced the COVID-19 spread. Without the containment policy, spreading of COVID-19 will reach 8,532,795 of total confirmed case. Whereas, without containment policy in West Java's Province the case will reach about $8,202,485$ of total confirmed case. Whether this number plausible or not, we can compared the results with Hsiang et al., (2020) study. In their study the number of confirmed case for China, Iran, and South Korea are extremely large. The confirmed case without containment policy reach 37 million confirmed cases in China, South Korea about 12 million cases, and Italy about 2.1 million cases. While they using only confirmed case and news data, they does not account for mobility networks.

In this paper, the model I built based upon interaction mobility networks as noted by Charu et al. (2017) and Gatto et al. (2020). The results of my paper will have more robust than Hsiang et al. (2020) due to human mobility interaction dataset. 
Figure 23. The Impact of DKI's PSBB Policy on Indonesia

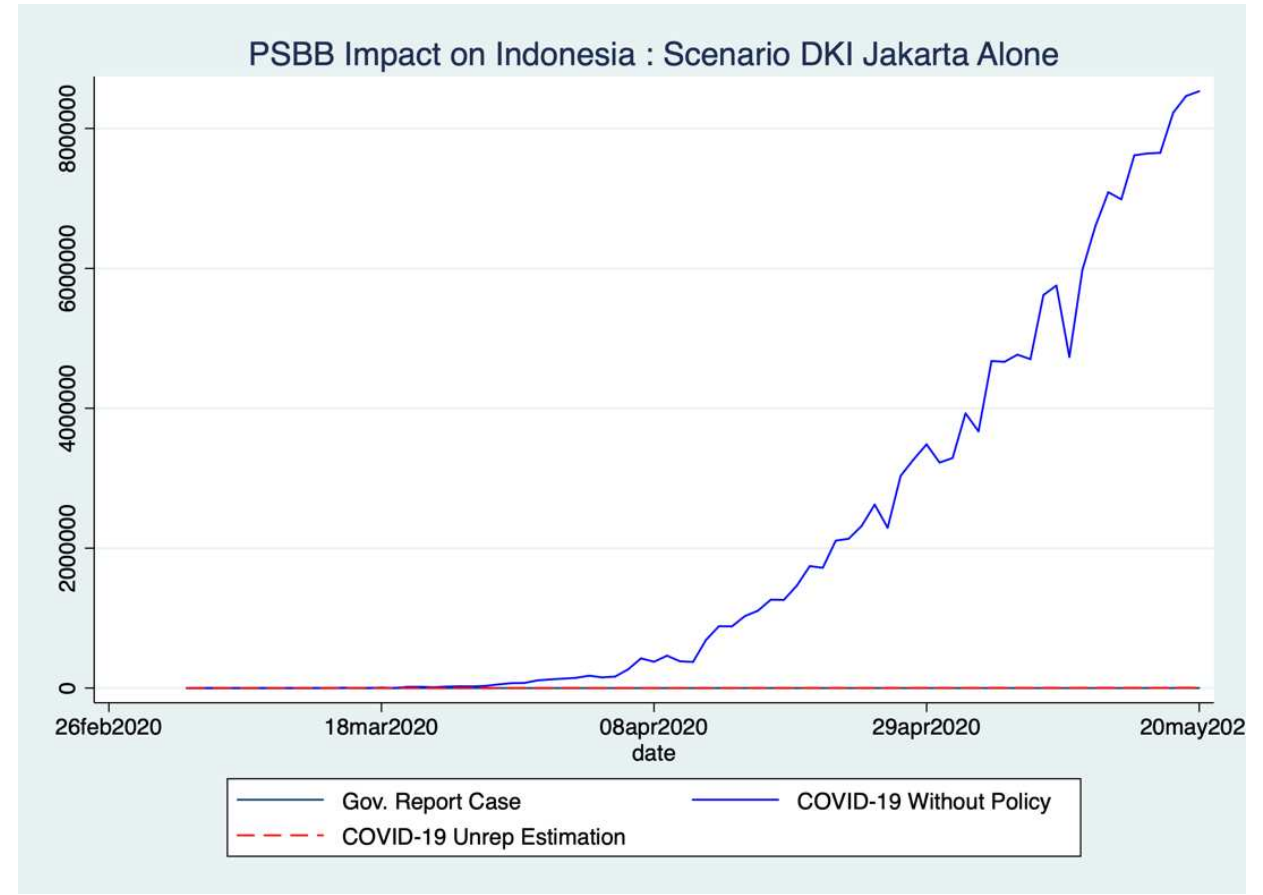

Figure 24. The Impact of West Java's PSBB Policy on Indonesia

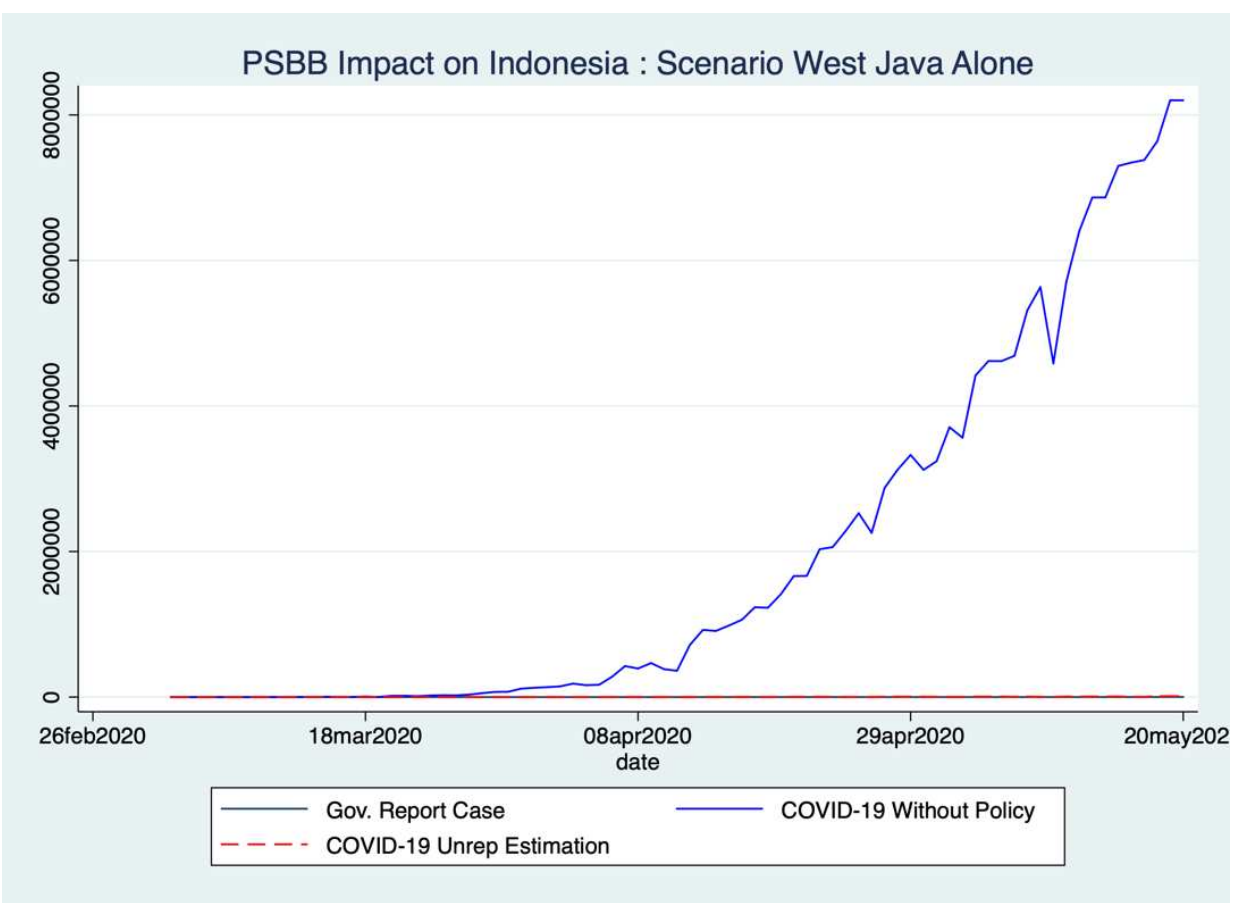

After we discuss about without policy option, now I depicted the predicted cases from the model along with proper data mobility across Indonesia. Where mostly dataset of Car Congestion Report in Java Island as well as the COVID-19 confirmed case. I focus the prediction in Java Island. In Table 7 and Table 8 were reported predicted unreported case in the region. 
The predicted report based upon average additional data case since the firs confirmed case and end of May 2020. The model predicted that containment policy impact in DKI Jakarta is lowered than West Java Province. While unreported case in DKI Jakarta predicted 160\% - 180\% higher than reported case. In West Java Province modeled predicted 220\% - 300\% higher than DKI Jakarta Province.

Table 7. Predicted Unreported Case in Java due to DKI Jakarta's PSBB

\begin{tabular}{|l|r|r|r|}
\hline \multicolumn{1}{|c|}{ Province } & $\begin{array}{c}\text { Add. Case Average in } \\
\text { Daily (Real Data) }\end{array}$ & $\begin{array}{c}\text { Add. Case Average in } \\
\text { Daily (Prediction) }\end{array}$ & $\begin{array}{c}\text { Ratio Predicted } \\
\text { / Actual (in \%) }\end{array}$ \\
\hline DKI Jakarta & 2,593 & 3,690 & 162.6 \\
\hline West Java & 774 & 1,531 & 183.6 \\
\hline Central Java & 501 & 865 & 186.0 \\
\hline DI Yogyakarta & 81 & 118 & 180.7 \\
\hline East Java & 804 & 1,186 & 188.0 \\
\hline Banten & 324 & 716 & 184.5 \\
\hline
\end{tabular}

Table 8. Predicted Unreported Case in Java due to West Java's PSBB

\begin{tabular}{|l|r|r|r|}
\hline \multicolumn{1}{|c|}{ Province } & $\begin{array}{c}\text { Add. Case Average in } \\
\text { Daily (Real Data) }\end{array}$ & $\begin{array}{c}\text { Add. Case Average in } \\
\text { Daily (Prediction) }\end{array}$ & $\begin{array}{c}\text { Ratio Predicted / } \\
\text { Actual (in \%) }\end{array}$ \\
\hline DKI Jakarta & 2,593 & 6,595 & 245.8 \\
\hline West Java & 774 & 2,890 & 300.9 \\
\hline Central Java & 501 & 1,118 & 240.0 \\
\hline DI Yogyakarta & 81 & 141 & 223.3 \\
\hline East Java & 804 & 1,553 & 250.4 \\
\hline Banten & 324 & 918 & 238.5 \\
\hline
\end{tabular}

These results strengthening my previous argument that containment policy will work effectively if the region within optimal area can control human mobility. The containment policy in DKI Jakarta is effectively reduce spread of COVID-19 spread due to its specific area because its capital city. Whereas, West Java with vast area and only specific area such as district level (such as City of Bogor, District Bogor, City Bekasi, District of Bekasi, City of Depok, City of Bandung, District of Bandung, and District of Bandung Barat - 8 city and district level out of 27 districts and cities level across West Java) which indicated as red zone has less effective than DKI Jakarta.

The higher unreported case in Table 7 and Table 8, informed us that government should aware and conduct more test to the people. This action will assists government to conduct effective policy such as advance containment policy and isolate more people who infected by COVID-19. The test could be take an action in every public and private institution. The new normal era should be engage with this policy to avoid more confirm COVID-19 case. 


\section{Conclusion and Recommendation}

I conclude that detailed information of human mobility with car congestion report can be employed to predict COVID-19 case. The reconciliation dataset between human mobility with detailed level and aggregated confirmed case robustly predict unreported case as well as with and without containment policy option. Limiting containment policy into specific area will be very effective to reduce the COVID-19 spread. The government should be aware, force and assist people awareness of social distancing protocol. When this policy unguided properly the COVID-19 case will be spread fast. While Indonesia's government support for new normal era, this policy should be guided precisely and practically. On the other hand, if we looking at the results and data, un awareness of people to concern about COVID-19 can be compensated by forcing law enforcement scenarios. There is no economic activity without safety and security first.

While the model only focus on spatial interaction between human mobility and COVID-19 confirmed case. Another control factors such as social information in sub district level and settlement information in sub district level (i.e. mosque, mall, modern market, traditional market) can be crucial factor that trigger human mobility covariates for advanced modeling. We can investigates how the policy can be effectively restrict the human mobility with the respective policy that conducted by Indonesian government. Another challenging issues, while the COVID-19 confirmed case data available in district level still inconsistent. The further analysis can be valuable to be investigates. We need more information dataset especially more human mobility data outside of Java. Although the car congestion report can be valid in Java region, but sample of car congestion report outside Java Island is not quite enough to predict human mobility report. We need more sample and representative mobility report to predict the COVID-19 confirm case.

\section{Acknowledgement :}

I highly appreciated for Waze Inc. which provide the dataset and join me in partnership lead of Waze Cities Partner. There is no funding to support this study. 


\section{Appendix}

In this appendix I demonstrates the optimal bandwidt with triangular kernel that indicated the various effect for each bandwidth in five scenarios.

Figure A- 1. Optimal Bandwidth DKI-West Java Interaction

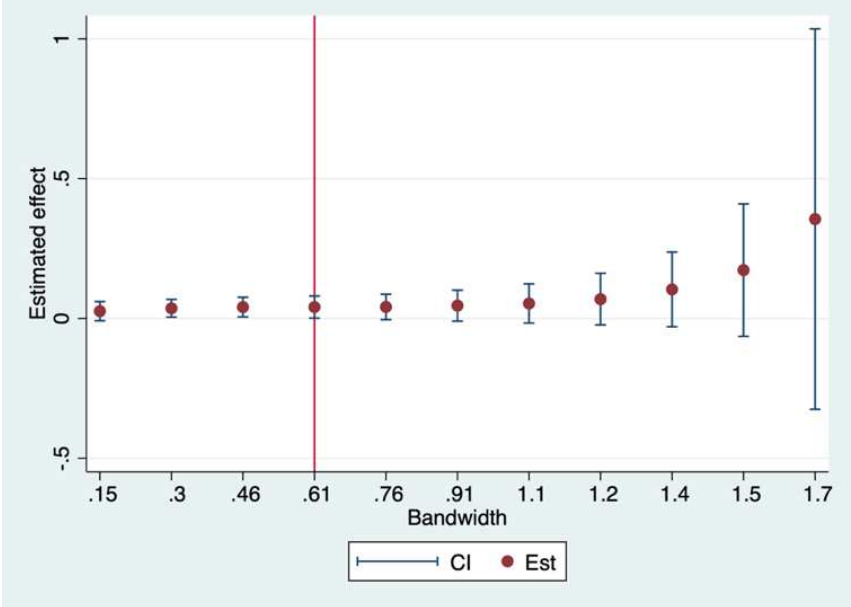

Figure A- 2. Optimal Bandwidth DKI-Banten Interaction

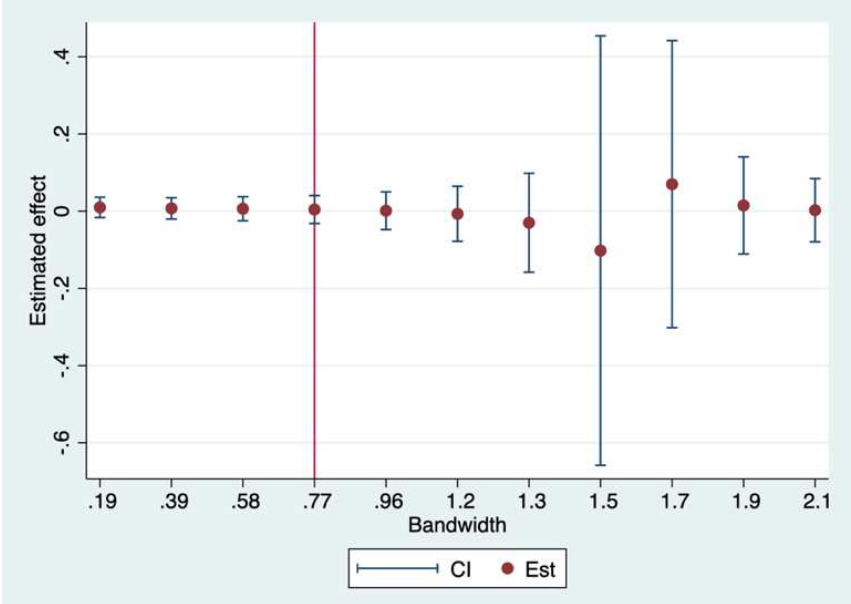


Figure A- 3. Optimal Bandwidth West Java-DKI Jakarta Interaction

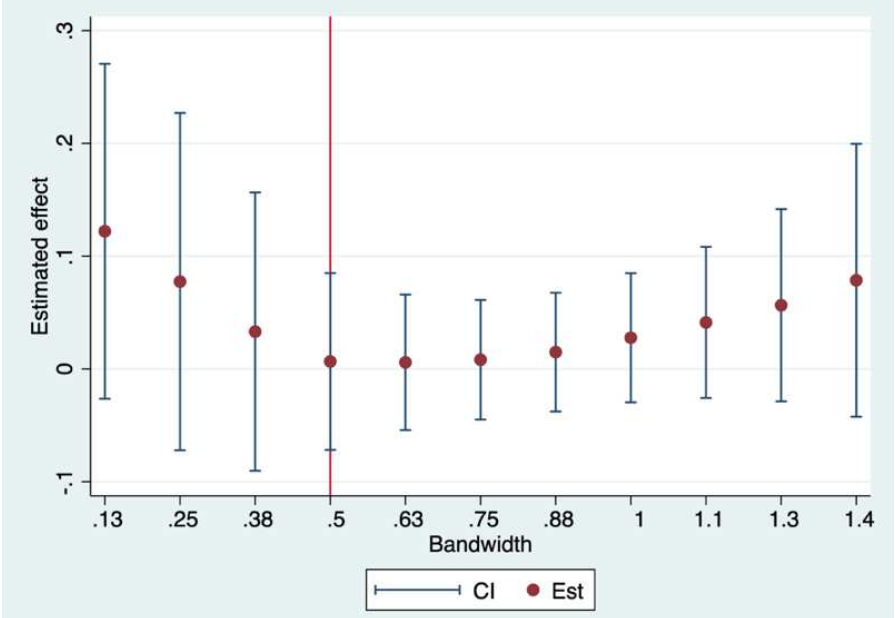

Figure A- 4. Optimal Bandwidth West Java-Banten Interaction

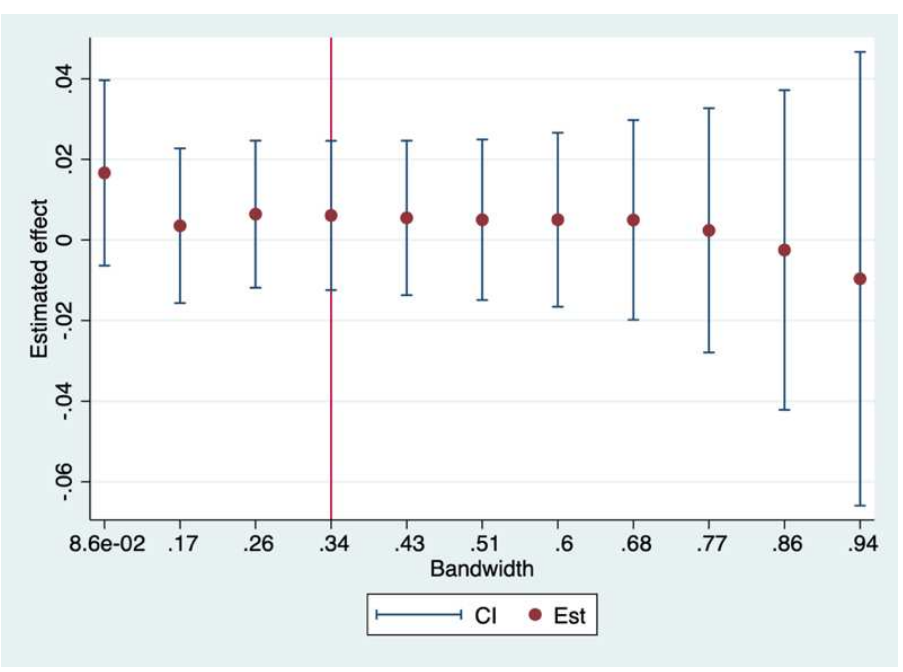

Figure A- 5. Optimal Bandwidth West Java - Central Java Interaction

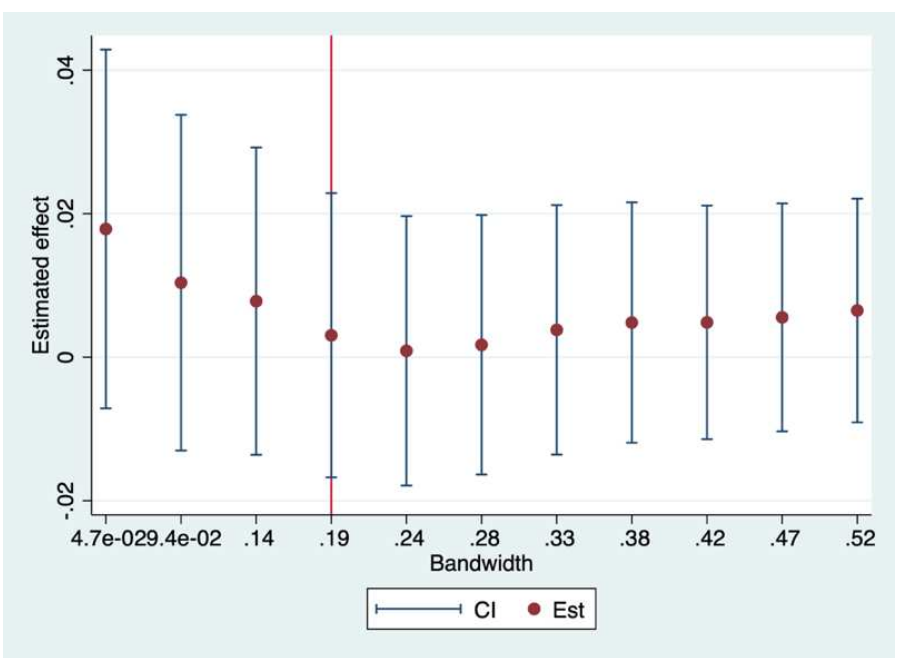




\section{References}

Alvarez, F., Argente, D. and Lippi, F. (2020) A Simple Planning Problem for COVID-19 Lockdown, EIEF Working Paper. 2005. Italy. doi: 10.2139/ssrn.3569911.

Charu, V. et al. (2017) 'Human mobility and the spatial transmission of influenza in the United States', PLoS Computational Biology, 13(2), pp. 1-23. doi: 10.1371/journal.pcbi.1005382.

Fogli, A. and Veldkamp, L. (2020) 'Germs, Social Networks and Growth', Review of Economic Studies, pp. 1-35. doi: 10.2139/ssrn.1679857.

Gatto, M. et al. (2020) 'Spread and dynamics of the COVID-19 epidemic in Italy: Effects of emergency containment measures', Proceedings of the National Academy of Sciences of the United States of America, 117(19), pp. 10484-10491. doi: 10.1073/pnas.2004978117.

Gelman, A. and Imbens, G. (2019) 'Why High-Order Polynomials Should Not Be Used in Regression Discontinuity Designs', Journal of Business and Economic Statistics, 37(3), pp. 447-456. doi: 10.1080/07350015.2017.1366909.

Hanming, F., Wang, L. and Yang, Y. (2020) Human mobility restriction and the spread of the novel corona virus (2019-NCov) in China. w26906. Cambridge, MA 02138.

Hellewell, J. et al. (2020) 'Feasibility of controlling COVID-19 outbreaks by isolation of cases and contacts', The Lancet Global Health, 8(4), pp. e488-e496. doi: 10.1016/S2214-109X(20)300747.

Hsiang, S. et al. (2020) 'The effect of large-scale anti-contagion policies on the COVID-19 pandemic.', Nature. doi: 10.1038/s41586-020-2404-8.

Imbens, G. and Kalyanaraman, K. (2012) 'Optimal bandwidth choice for the regression discontinuity estimator', Review of Economic Studies, 79(3), pp. 933-959. doi: 10.1093/restud/rdr043.

Imbens, G. W. and Lemieux, T. (2008) 'Regression discontinuity designs: A guide to practice', Journal of Econometrics, 142(2), pp. 615-635. doi: 10.1016/j.jeconom.2007.05.001.

Keele, L. J. and Titiunik, R. (2015) 'Geographic boundaries as regression discontinuities', Political Analysis, 23(1), pp. 127-155. doi: 10.1093/pan/mpu014.

Lee, D. S. and Lemieux, T. (2010) 'Regression Discontinuity Designs in Economics', Journal of Economic Literature 48, 48(1), pp. 281-355.

McCrary, J. (2008) 'Manipulation of the running variable in the regression discontinuity design: A density test', Journal of Econometrics, 142(2), pp. 698-714. doi: 10.1016/j.jeconom.2007.05.005.

Pepe, E. et al. (2020) 'COVID-19 outbreak response: a first assessment of mobility changes in Italy following national lockdown', medRxiv, p. 2020.03.22.20039933. doi: 10.1101/2020.03.22.20039933.

Roberts, M., Sander, F. G. and Tiwari, S. (2019) Time to Augment, Connect, and Target (ACT) Realizing Indonesia's Urban Potential.

Wooldridge, J. M. (2016) Econometrics: A modern approach. Boston, USA.: Cengange Learning. 
